\title{
Respuestas del sistema diplomático ante el Servicio Europeo de Acción Exterior (SEAE): el caso de la Unión Europea en la Asamblea General de las Naciones Unidas
}

\author{
Carmela Pérez Bernárdez \\ Profesora Ayudante Doctora en la Universidad de Granada, \\ Departamento de Derecho Internacional Público y Relaciones Internacionales
}

\begin{abstract}
Sumario: I. Introducción. - II. Efectos de la atribución de la personalidad jurídica internacional a la UE en el marco de las organizaciones internacionales. 1. Las nuevas delegaciones de la Unión. 2. La sustitución de la CE por la UE. - III. La compleja consolidación de un estatuto privilegiado para la UE en la Asamblea General de las Naciones Unidas. 1. El punto de partida: La participación de la UE en organizaciones internacionales. 2. Los antecedentes: La UE en la Asamblea General de las Naciones Unidas. 3. Los últimos desarrollos: el proyecto de resolución sobre la «participación de la UE en la labor de las Naciones Unidas».-IV. Reflexiones finales.
\end{abstract}

Resumen: El objeto de este trabajo consiste en analizar algunas de las modificaciones más relevantes que se están produciendo actualmente en torno a la participación de la Unión Europea (UE) en las organizaciones internacionales, como consecuencia de la entrada en vigor del Tratado de Lisboa y la puesta en marcha del Servicio Europeo de Acción Exterior. Los cambios que se están orquestando en las delegaciones de la Unión y, concretamente, las sitas en Ginebra y Nueva York - acreditadas ante numerosas organizaciones internacionales - , así como las distintas iniciativas de la UE tendentes a lograr una participación más activa en la Asamblea General de las Naciones Unidas - incluyendo la consolidación formal de un estatuto privilegiado - son expuestas con el fin de presentar algunos de los efectos derivados o impulsados por la atribución expresa de la subjetividad jurídica internacional a la UE.

Palabras clave: Unión Europea (UE), Organizaciones Internacionales, Naciones Unidas (NU), Acción Exterior, Delegaciones de la Unión.

Abstract: The purpose of this paper is to analyse some of the most recent changes that are currently taking place regarding the role of the European Union $(E U)$ as a member of International Organizations due to the entry into force of the Treaty of Lisbon and to the implementation of the European External Action Service (EEAS). The changes brought about in the Union delegations, especially in the ones located in Geneva and New York - accredited before many International Organizations-, and the various EU proposals focused on achieving a 
more active role in the United Nations General Assembly -including the formal recognition of an enhanced status - are described to study some of the effects caused or boosted by the explicit attribution of an international legal personality to the EU.

Key words: European Union, International Organizations, United Nations, External Action, Union Delegations.

\section{Introducción}

1. El trabajo que presento tiene por objeto analizar algunos de los cambios que se están introduciendo actualmente en torno a la participación de la Unión Europea (UE) en las organizaciones internacionales, como consecuencia de la entrada en vigor del Tratado de Lisboa y la puesta en marcha del Servicio Europeo de Acción Exterior (SEAE).

La relevancia que han adquirido en nuestros días las organizaciones internacionales se hace evidente al examinar el papel que desarrollan en la sociedad internacional las casi 400 estructuras institucionales de cooperación tendentes a la realización de diversos objetivos necesitados de una concertación multilateral.

La Unión Europea, habida cuenta de sus competencias, desea y necesita intervenir de manera más intensa y coherente en las organizaciones internacionales. La heterogénea participación de la UE en calidad de miembro y sobre todo de observador - privilegiado frecuentemente - en los órganos de distintas organizaciones universales y regionales, nos lleva a un vasto terreno gobernado por normas muy variadas. Por ello, he seleccionado como sujeto de análisis, que nos sirva de referente, a la Asamblea General de las Naciones Unidas (a partir de ahora, AGNU). En este órgano plenario de las Naciones Unidas, desde el que se toma el pulso a la sociedad internacional - gracias al mantenimiento de la regla de un voto para cada Estado miembro y a su gran porosidad al tratar las cuestiones que preocupan al conjunto de dicha sociedad - se están haciendo especialmente visibles las iniciativas de la UE para adaptarse a los cambios introducidos en su representación externa.

2. Con el propósito de ilustrar este escenario de cambios y comprobar su impacto en la Unión, sus Estados miembros y terceros - países y organizaciones internacionales -, me ocuparé, en la primera parte de este trabajo (II.) de sintetizar los efectos desencadenados por la atribución explícita de la subjetividad jurídico-internacional a la Unión Europea en el marco de las organizaciones internacionales, destacando la conversión de las delega- 
ciones de la Comisión en delegaciones de la Unión y ciertos cambios que se están produciendo en el seno de éstas, como en las establecidas en Ginebra y Nueva York y acreditadas ante numerosas organizaciones internacionales (1.). Asimismo, daré cuenta de cómo se está produciendo la sustitución de la Comunidad Europea (CE) por la UE en el marco de las organizaciones internacionales (2.). En la segunda parte de la investigación (III.), comenzaré exponiendo - como punto de partida para situar adecuadamente el caso de análisis seleccionado - los actuales modos de participación de la UE con organizaciones internacionales, contrastando la práctica heterogénea existente con la limitada regulación jurídica incluida en el Derecho primario sobre esta materia (1.). Finalmente, tras echar la vista atrás para conocer la evolución de la UE ante la AGNU (2.), daré cuenta del iter que aquélla atraviesa para lograr la intervención en dicho órgano de los responsables de exteriores de la Unión establecidos por el Tratado de Lisboa -el Alto Representante para Asuntos Exteriores y Política de Seguridad y el Presidente del Consejo Europeo- y, en definitiva, un estatuto más activo en la AGNU (3).

\section{Efectos de la atribución de la personalidad jurídica internacional a la UE en el marco de las organizaciones internacionales}

3. La atribución explícita de la personalidad jurídica - internacionala la UE se incluye, por fin, en el más lacónico de los artículos del Tratado de la UE (TUE) en su última versión (Lisboa) ${ }^{1}$, que reproduce en su artículo 47 la disposición recogida anteriormente en el fallido Tratado Constitucional.

Desde que la UE se estableció en 1992, como entidad política y jurídica, que acogía dentro de su estructura a las Comunidades Europeas (vid. antiguo art. 1 TUE) $)^{2}$, las distintas reformas de los Tratados constitutivos han

${ }^{1}$ El artículo 47 TUE señala: «La Unión tiene personalidad jurídica». Se entiende «internacional», aunque la redacción de la disposición no lo indique expresamente. Vid. la «mojigata» Declaración n..$^{\circ} 24$ aneja al Tratado de Lisboa, a gusto de los países que integran la Unión, que recoge una afirmación - innecesaria - relativa a la salvaguarda de las competencias de los Estados miembros no atribuidas en los Tratados.

${ }^{2}$ El antiguo artículo 1 TUE señalaba en su párrafo $3 .^{\circ}:$ «La Unión tiene su fundamento en las Comunidades Europeas completadas con las políticas y formas de cooperación establecidas por el presente Tratado». La referencia a las Comunidades Europeas -insertadas dentro de la UE a modo de muñeca rusa-, incluía hasta tres sujetos de Derecho internacional diferentes: en primer lugar, la Comunidad Europea (CE), cuyo antiguo artículo 281 del Tratado constitutivo de la CE (TCE) le confería, con una fórmula similar al actual artículo 47 TUE, la personalidad jurídica, y que el Tribunal de Justicia de la UE, desde el asunto AETR interpretó 
barajado, en sus conferencias intergubernamentales, propuestas para dotar a este ente complejo de subjetividad jurídico-internacional ${ }^{3}$.

El resultado desequilibrado recogido en el TUE en su versión de Ámsterdam en 1999 permitía que, si bien, por un lado, la Unión pudiera concluir acuerdos internacionales con terceros Estados y organizaciones internacionales en los dos ámbitos de cooperación fundamentalmente intergubernamental - la Cooperación Policial y Judicial en materia Penal (CPJP) y la Política Exterior y de Seguridad Común (PESC) ${ }^{4}$-, por otro, no se le atribuyera de forma expresa la personalidad jurídica internacional. Esta situación, en virtud de la cual se concede a un organismo internacional - en este caso a uno especialmente desarrollado como la UE - capacidades típicas de sujetos de Derecho internacional, sin llevar aparejado el reconocimiento explícito en el articulado de su subjetividad jurídica internacional, esconde, en el caso de la UE, ciertas reticencias de los Estados miembros hacia el reconocimiento expreso de que la criatura que crean está capacitada para li-

como «internacional» - cfr. asunto 22/70, Comisión/Consejo Sentencia del Tribunal de Justicia de las Comunidades Europeas (TJCE) de 31 de marzo de 1971, Rec. 1971, pp. 263 y ss. - ; en segundo lugar, la Comunidad Europea del Carbón y del Acero (CECA), la primera de las creadas y desaparecida en 2002 y, en tercer lugar, la Comunidad Europea de la Energía Atómica (CEEA o EURATOM), que no ha sido absorbida por la UE tras la reforma operada por el Tratado de Lisboa, lo que hubiera sido preferible a efectos de simplicidad. En definitiva, actualmente continuamos teniendo dos sujetos de Derecho internacional diferentes: la UE y la CEEA.

3 Hace ya más de una década, en 1996 durante los trabajos de la Conferencia Intergubernamental tendentes a adoptar el Tratado de Ámsterdam, la Presidencia irlandesa del Consejo introdujo varias opciones en torno a la atribución de dicha subjetividad — una opción A con dos variantes, la primera, manteniendo las de las Comunidades Europeas y, la segunda, fusionándolas en una única, así como una opción B, que proporcionaba sólo la capacidad de celebrar tratados internacionales en los dos ámbitos de cooperación intergubernamental-. Finalmente, los efectos de los juegos malabares en la fase final de esta Conferencia Intergubernamental llevaron a los Estados miembros a aceptar un resultado desequilibrado, impidiendo que la posición audaz mantenida por la Presidencia siguiente - holandesa - saliera adelante. Dicha propuesta consistía en introducir un audaz artículo A que fusionara todas las personalidades jurídicas en una sola y única de la Unión. Cfr. sobre estas cuestiones, PAPATHANASIOU, I., «The European Union's Identity as a Subject of the International Legal Order: Evolutions under the Treaty of Lisbon» en Cambridge Student L. Rev. 22, 5, 2009, pp. 22-39, especialmente, pp. 28 y 32; PÉREZ BERNÁRDEZ, C., Las relaciones de la Unión Europea con Organizaciones Internacionales: Análisis jurídico de la práctica institucional, Dirección General de Universidades, Madrid, 2003, pp. 73-79 y 101-133; PEREZ GONZÁLEZ, M. y STOFFEL VALLOTON, N., «La cuestión de la naturaleza jurídica de la Unión: el problema de la personalidad jurídica» en OREJA AGUIRRE, M. (dir.), El Tratado de Ámsterdam: Análisis y comentarios, vol. I, McGraw-Hill, Madrid, 1998, pp. 187-199.

${ }^{4}$ Cfr. los antiguos artículos 24 y 38 TUE que - al contrario que el actual art. 216 TFUE - llaman la atención por la falta de claridad en la identificación del sujeto de Derecho internacional que concluye el acuerdo, ya que la UE como tal, no aparecía en dichas disposiciones. 
diar en la escena internacional ${ }^{5}$. Empero, este comportamiento no es ajeno a la práctica institucional, ya que continúa siendo una excepción la inclusión en los tratados constitutivos de organizaciones internacionales de cláusulas que de forma explícita recogen la subjetividad internacional de los entes que crean ${ }^{6}$.

Junto a la capacidad convencional de la UE, que constituye la manifestación por antonomasia de los sujetos de Derecho internacional, la Unión mostraba otras singularidades propias de sujetos de Derecho internacional, por ejemplo, en su relación con distintas organizaciones internacionales, diferenciada de la Comunidad Europea (CE), que mantuvo su propia personalidad jurídica hasta la entrada en vigor del Tratado de Lisboa el 1 de diciembre de 2009. De hecho, en las relaciones con organizaciones internacionales, se hacía cada vez más evidente que ni la CE ni sus Estados miembros se encontraban legitimados para asumir ciertas obligaciones internacionales que escapaban de su ámbito competencial. Por lo tanto, la UE actuaba, en ocasiones, de facto como un sujeto de Derecho internacional, situación que daba lugar a confusiones frente a terceros y en el seno de la Unión?

Por ello, la atribución expresa de la personalidad jurídica a la UE en el artículo 47 del TUE, unida al hecho de que la Unión sustituye y sucede a la Comunidad Europea (art. 1 in fine TUE) ${ }^{8}$, constituye una modificación apa-

5 Vid. PÉREZ GONZÁLEZ, M. y STOFFEL VALLOTON, N., op. cit., nota 3, pp. 192-195.

${ }^{6}$ V.g., sí que aparece en relación con la Autoridad Internacional de los Fondos Marinos (art. 176 de la Convención de las Naciones Unidas para el Derecho del Mar de 1982) o en el art. 34 del Protocolo adicional al Tratado de Asunción sobre la estructura institucional del MERCOSUR, de 1994 (conocido como el Protocolo de Ouro Preto).

7 Por ejemplo, al año siguiente de entrar en vigor el Tratado creador de la UE, en 1994, ésta intervenía y aparecía como responsable del Memorando de acuerdo sobre la administración de Mostar pese a que fue firmado por - la compleja fórmula siguiente - la Presidencia en nombre de los «Estados miembros de la UE actuando en el marco de la Unión y en plena asociación con la Comisión Europea». Otro ejemplo muestra como en 2001, en el marco de las relaciones con la Organización Internacional del Trabajo (OIT) se concluyó un Canje de Notas por la Comisión, en nombre de la CE, de un lado y, el Director General de la OIT, por otro, que incluía, en su parte dispositiva, numerosas referencias a la UE, pese a que ésta no intervenía como parte en este acuerdo que formalizaba las relaciones de carácter administrativo entre ambos organismos. Cfr. FERNÁNDEZ ARRIBAS, G., Las capacidades de la Unión Europea como sujeto de Derecho Internacional, Educatori, Granada, 2010, p. 68; PÉREZ BERNÁRDEZ, C., op. cit., nota 3, pp. 110 y 409.

${ }^{8}$ El Tratado de Lisboa incorpora el párrafo $3 .^{\circ}$ al art. 1 TUE que señala in fine: «La Unión sustituirá y sucederá a la Comunidad Europea». El mantenimiento de la CE y de la UE - habiendo atribuido expresamente a ésta la personalidad jurídica internacional, como contemplaban propuestas de reforma del Derecho originario anteriores al Tratado de Lisboahubiera tenido un efecto negativo, consolidando una situación generadora de confusiones importantes, que se estaban produciendo ya de facto. 
rentemente técnica, pero que tiene importantes efectos colaterales y clarificantes, de los que daré cuenta seguidamente ${ }^{9}$, deteniéndome en los que tienen un mayor impacto en el ámbito objeto de este trabajo:

\section{Las nuevas delegaciones de la Unión}

4. La conversión de las antiguas «delegaciones de la Comisión Europea» en «delegaciones de la Unión», que realiza el Tratado de Lisboa, viene a saldar una vieja cuenta pendiente desde el arranque del proceso de integración europea. Los consensos necesarios para abrir las delegaciones de la Comisión al personal de otras instituciones europeas y transformarlas en delegaciones «de la Comunidad Europea», nunca se consiguieron. Por ello, la decisión de atribuir expresamente la subjetividad jurídica internacional a la Unión y reunir - por fin - en una única entidad a la antigua UE y la CE impulsó claramente la adopción de esta medida, más acorde con las necesidades de representación exterior sobre el terreno de una UE renovada.

La conversión, que actualmente se está llevando a cabo, de las delegaciones lleva aparejada importantes modificaciones internas, así como otras perceptibles en la vertiente externa $-v . g$., relativas a la representación del personal de estas delegaciones en organizaciones internacionales, en línea con lo señalado en el artículo 221.1. ${ }^{\circ}$ del TFUE ${ }^{10}$, asumiendo

9 En este aspecto discrepo de la postura defendida por PAPATHANASIOU, en virtud de la cual el reconocimiento expreso de la personalidad jurídica internacional a la UE introducido por el Tratado de Lisboa debería entenderse como un «cambio puramente técnico», ya que existía, de forma implícita, con el antiguo TUE. Vid. PAPATHANASIOU, I., op. cit., nota 3, p. 35. Dicha afirmación no tiene en consideración los efectos colaterales de arrastre que dicha atribución explícita lleva consigo, entre ellos, los relacionados con las nuevas responsabilidades que incumben ya a la UE en materia de representación exterior en el seno de las organizaciones internacionales. Y ello, independientemente de que más que de una «sucesión» de una organización internacional por otra, nos encontremos ante una mera «continuación» de la CE y de la antigua UE por la nueva UE.

${ }^{10}$ El artículo 221 del Tratado de Funcionamiento de la UE (TFUE) señala, de forma general, que «las delegaciones de la Unión en terceros países y ante organizaciones internacionales asumirán la representación de la Unión» (art. 221.1. ${ }^{\circ}$ TFUE); asimismo indica que «estarán bajo la autoridad del Alto Representante de la Unión» y que «actuarán en estrecha cooperación con las misiones diplomáticas y consulares de los Estados miembros» (art. 221.2. ${ }^{\circ}$ TFUE). También encontramos otras referencias a las nuevas «delegaciones de la Unión» en el TUE, cuyas disposiciones, básicamente, ponen el acento la búsqueda de la coherencia de la Unión a través de su actuación (arts. 32 in fine y 35 TUE). El artículo 32 in fine TUE señala que las delegaciones de la Unión y las misiones diplomáticas de los Estados miembros en los terceros países y ante organizaciones internacionales «cooperarán entre sí y contribuirán a la formulación y puesta en práctica» de un enfoque común. En esta línea, el artículo 35 TUE incluye también, junto a los anteriores sujetos, a las misiones consulares de los 
nuevas funciones desempeñadas anteriormente por la Presidencia rotatoria del Consejo- ${ }^{11}$.

5. Con anterioridad a la entrada en vigor del Tratado de Lisboa, la Comisión Europea fue el órgano que se ocupó del ius legationis, ejercido conjuntamente con las misiones diplomáticas y consulares de los Estados miembros y con un protagonismo del Estado que ejerce la Presidencia rotatoria del Consejo. La Comisión consiguió tejer una red tupida de delegaciones acreditadas ante más de 140 Estados, así como en 8 ciudades que acogen distintas sedes de organizaciones internacionales (Ginebra, Nueva York, París, Viena, Roma, Nairobi, Addis-Abeba y Estrasburgo) ${ }^{12}$.

En la actualidad, todas ellas se han reconvertido en delegaciones de la Unión, o están sumergidas en dicho proceso. Así, coincidiendo con la entrada en vigor del Tratado de Lisboa, la UE ha cambiado la denominación

Estados miembros y las representaciones ante conferencias internacionales que, «cooperarán para garantizar el respeto y la ejecución de las decisiones que establezcan posiciones o acciones de la Unión».

${ }^{11}$ En la actualidad el ejercicio por parte de la Unión del derecho de legación en su vertiente activa se encuentra muy desarrollado, asemejándose cada vez más al ejercido por los Estados, y distanciándose del desarrollado de manera ordinaria por las organizaciones internacionales. Constituye, además, otro de los rasgos más característicos de la UE como sujeto de Derecho internacional. Sobre el derecho de legación y las dificultades para conseguir un ius omnimodae repraesentationis, cfr. SOBRINO HEREDIA, J.M., «La actividad diplomática de las delegaciones de la Comisión en el exterior de la Comunidad Europea» en RIE, vol. 20, n. ${ }^{\circ}$ 2, 1993, pp. 485-532, especialmente pp. 485-492; asimismo, un estudio detallado sobre el tema puede encontrarse en la monografía de SÁNCHEZ RAMOS, B., La Unión Europea y las relaciones diplomáticas, Tirant lo Blanch, monografías 329, Valencia, 2004.

12 En Ginebra se encuentra sita, por ejemplo, una de las sedes más emblemáticas de las Naciones Unidas y algunas de sus agencias especializadas, como la OIT, la Organización Mundial de la Salud (OMS), la Organización Mundial de la Propiedad Intelectual (OMPI), así como la Organización Mundial del Comercio (OMC); en Nueva York se encuentra la sede de las Naciones Unidas que alberga a la Asamblea General y al Consejo de Seguridad; en París se encuentra la Organización de las Naciones Unidas para la Educación, la Ciencia y la Cultura (UNESCO) y la Organización para la Cooperación y Desarrollo Económicos (OCDE); en Viena está la sede de distintos organismos de las NU, el Organismo Internacional de la Energía Atómica (OIEA), la Organización para la Seguridad y Cooperación en Europea (OSCE) y la Organización de Países Exportadores de Petróleo (OPEP), entre otros; en Roma se encuentra una delegación acreditada ante la Organización de las Naciones Unidas para la Alimentación y la Agricultura (FAO), de la que la UE es miembro de pleno derecho junto a sus Estados miembros, y existen otras entidades relacionadas con la agricultura y la alimentación, como el Programa Mundial de Alimentos (PMA) y el Fondo Internacional de Desarrollo Agrícola (FIDA); en Nairobi, la representación europea está acreditada ante el Estado keniata, pero también ante Hábitat, que es el Programa de las Naciones Unidas para los Asentamientos Humanos, y el Programa de las Naciones Unidas para el Medio Ambiente (PNUMA). En Addis-Abeba, se encuentra acreditada la delegación de la Unión para Etiopia y ante la Unión Africana. Finamente, en la ciudad francesa fronteriza de Estrasburgo se ha abierto una representación de la UE acreditada ante el Consejo de Europa. 
de sus delegaciones en terceros Estados y organizaciones internacionales - antes «de la Comisión Europea» y ahora «de la Unión Europea»como puede comprobarse físicamente en las placas de las sedes de las delegaciones y en el listado de dichas legaciones recogido en la página web de la UE ${ }^{13}$. Así, por ejemplo, la UE, durante la Presidencia rotatoria sueca y española del segundo semestre de 2009 y primero del 2010, respectivamente, ha llevado a cabo campañas de información sobre las modificaciones de dichas delegaciones ante terceros, dirigidas, inter alia, a las representaciones permanentes de Estados y de observadores de distintas organizaciones internacionales - como detallaré en el apartado siguiente, 2.- .

6. Con el Tratado de Lisboa y la puesta en marcha del SEAE, la composición de las delegaciones cambia, abriéndose al personal del Consejo de la Unión y a diplomáticos de los Estados miembros, que vienen a unirse al contingente ya existente de la Comisión (art. 27.3. ${ }^{\circ}$ TUE y art. 6 de la Decisión del Consejo de 26 de julio de 2010 por la que se establece la organización y el funcionamiento del Servicio Europeo de Acción Exterior) ${ }^{14}$. De esta forma las delegaciones, haciendo honor a su nombre, representan ya oficialmente a la UE, y no sólo a la Comisión - como ocurría antes de

13 El listado de delegaciones que enlaza con sus respectivas páginas web es accesible en http://ec.europa.eu/external_relations/delegations/web_en.htm. Las Delegaciones de la antigua Comisión Europea en Azerbaiyán, Corea del Sur o Singapur, por ejemplo, hicieron pública su nueva condición de Delegaciones de la Unión Europea de forma más tardía, el 1 de julio de 2010.

${ }^{14}$ Cfr. dicha Decisión del Consejo en DO L 201, 3.8.2010, pp. 30-40. Aunque el SEAE fuera lanzado oficialmente el 1 de diciembre de 2009 - coincidiendo con la entrada en vigor del Tratado de Lisboa-, su puesta en marcha se está realizando por etapas, habiendo quedado realmente operativo a partir del 1 de enero de 2011. Así, a principios de 2011, 1.643 funcionarios han sido transferido desde los servicios de la Comisión y del Consejo de la Unión al nuevo SEAE. En concreto, 585 funcionarios proceden de la Dirección General (DG) RELEX de la Comisión en Bruselas - dicha DG dejará de existir-, 93 de la DG de Desarrollo, 436 que se encuentran actualmente trabajando en las delegaciones de la Unión Europea en terceros países y organizaciones internacionales y 411 proceden de la DG de Asuntos Exteriores y Político-Militares de la Secretaría del Consejo de la Unión. A ellos se unirán los 118 nuevos puestos, que se crearán durante el año 2011. Cfr. Bulletin Quotidien Europe 10283, 23/12/2010, p. 4 y «2011 - A new set-up for Commission external relations staff», Comissi on Plus n. ${ }^{\circ}$ 580, 1, 14.01.2011. Sobre el establecimiento y las realizaciones del SEAE, pueden consultarse: ALDECOA, F. y GUINEA, M., «Nace la diplomacia común de la Unión Europea» en Política Exterior, Julio/Agosto 2010, pp. 62-74; PÉREZ BERNÁRDEZ, C., «Hacia el complejo establecimiento de un Servicio Europeo de Acción Exterior: Las futuras embajadas de la Unión Europea» en La Proyección Exterior de la Unión Europea: Desafios y Realidad, Tirant monografías 483, Valencia, 2007, pp. 57-114; «Un órgano in statu nascendi: El Servicio Europeo de Acción Exterior (SEAE) Post-Lisboa» en SOBRINO HEREDIA, J.M. (dir.), Innovación y Conocimiento, IV Jornadas Iberoamericanas de Estudios Internacionales, Lisboa, 23, 24 y 25 de noviembre 2009, Marcial Pons, Madrid, 2010, pp. 457-469. 
producirse esta conversión- $-{ }^{15}$. Las delegaciones de la Unión, que constituyen la pieza clave de la Unión sobre el terreno en terceros Estados y en organizaciones internacionales, unidas a la administración central con sede en Bruselas, conforman el SEAE (arts. 1.4. ${ }^{\circ}$ y 5 de la Decisión del Consejo de 26 de julio de 2010).

Ahora bien, pese a que las delegaciones de la Comisión hayan representado a la Comisión ante terceros, paulatinamente y, de facto, fueron ampliando su función y representando no sólo a la - ya desaparecidaCE, sino también, en ciertos aspectos, a la UE tras su creación en 1992, aun cuando no se le había reconocido formalmente una subjetividad jurídico-internacional. Esta atribución implícita, desarrollada progresivamente por las delegaciones de la Comisión, consecuentemente, forzaba aún más la necesidad de rebautizar y reformar las representaciones de la Comisión ante terceros ${ }^{16}$.

7. Las delegaciones de la Unión, incluyendo las sitas en Ginebra y en Nueva York acreditadas ante las NU y otras organizaciones internacionales, se encuentran orquestando cambios que afectan tanto a la estructura organizativa interna, como a la proyección ad extra de la actividad de la UE, todo ello como consecuencia de las modificaciones introducidas por la entrada en vigor del Tratado de Lisboa en materia de acción exterior y la puesta

15 En septiembre de 2010, en una primera ronda, la Alta Representante de la Unión para Asuntos Exteriores y Política de Seguridad, la Sra. Catherine Ashton, ha nombrado a 28 Jefes de Delegaciones de la UE y un Jefe Adjunto. Trece se han adjudicado a diplomáticos procedentes de Estados miembros - incluyendo los importantes destinos de China, Japón, y Sudáfrica- y dieciséis a la Comisión Europea. Cfr. VOGEL, T., Ashton names EU ambassadors, 15.09.2010, en www.europeanvoice.com No obstante, algún autor destaca, en este primer estadio de implementación del SEAE, cómo la Comisión, en numerosas delegaciones, ha asumido la representación de la Unión sin una participación real de los Estados miembros, teniendo en cuenta la transferencia que se produce en este ámbito por parte de la Presidencia semestral y la lenta incorporación de diplomáticos procedentes de los Estados miembros. Vid. DASTIS QUECEDO, A., «La diplomacia tras el Tratado de Lisboa» en Innovación y Conocimiento, op. cit., nota 14, pp. 403-417, en concreto, pp. 413 y 414.

16 Existe cierto paralelismo entre la situación de facto mencionada respecto a la representación oficiosa de la UE por parte de las delegaciones de la Comisión y el hecho de que las nuevas delegaciones de la Unión asuman también la representación del EURATOM en terceros países y organizaciones internacionales, (cfr. el inciso 18 del preámbulo de la Decisión del Consejo de 26 de julio de 2010, loc. cit., nota 14, p. 32). Ello sucede sabiendas de que el Tratado de Lisboa no logró fusionar al EURATOM en la UE, por lo que mantiene su personalidad jurídica diferenciada, aunque comparta - como hacía antes con la CE, y previamente con la CECA - un único marco institucional. El EURATOM, por ejemplo, es miembro de la maltrecha Organización Internacional para el Desarrollo Energético de la Península de Corea (KEDO), que tiene su sede en Nueva York y a la que se adhirió en 1997, por lo que la Delegación de la Unión sita en esta ciudad, y acreditada ante numerosos organismos internacionales, se hará cargo de dicha representación. 
en marcha del SEAE. Son numerosas las cuestiones relativas al funcionamiento de las delegaciones de la Unión en las organizaciones internacionales que no están aún resueltas. En concreto, las condiciones en las que dichas delegaciones desarrollarán su labor ante estas organizaciones, debido a la necesidad de estudiar cada caso de forma individualizada, habida cuenta de las singularidades y reglas concretas de estos organismos, así como de las distintas competencias que tiene la Unión en los ámbitos en los que dichas organizaciones trabajan.

Desde esta perspectiva externa, por ejemplo, los trabajos a desarrollar por la Delegación de la Unión en Ginebra ante organizaciones internacionales serán más exigentes, al tener que coordinar la posición de la Unión en distintos foros de las Naciones Unidas, representar en ellos a la Unión - sustituyendo en esta función a los representantes estatales de la Presidencia rotatoria del Consejo - y, a la vez, llevar a cabo una intensa coordinación local con las misiones diplomáticas de los Estados miembros ${ }^{17}$. Internamente esta situación se traduce en la decisión, refrendada por la Comisión Europa en julio de 2010, de escindir esta Delegación de la Unión sita Ginebra en dos, de modo que, funcionen sendas representaciones de la Unión distintas, cada una de ellas con un Jefe de Delegación, que le permita asumir adecuadamente las nuevas responsabilidades ${ }^{18}$. Esta iniciativa se debe al incremento de trabajo que se ha producido en los últimos años en el marco de las NU y a la necesidad de continuar la absorbente labor que desempeña el

17 Cfr. Informe de la Presidencia al Consejo Europeo sobre el Servicio Europeo de Acción Exterior, Bruselas, 23 de octubre de 2009, Bruselas, 14930/09, POLGEN 163, p. 9 in fine. En él se pone de relieve que, desde la entrada en vigor del Tratado de Lisboa, las delegaciones de la Unión asumirán progresivamente cometidos mayores en la representación ante organizaciones internacionales, en detrimento de las funciones que anteriormente desempeñaba la Presidencia rotatoria de los Estados miembros del Consejo. Sobre esta cuestión, algún autor expresa con claridad su preocupación relativa a que la transferencia de la representación de la Unión desde la Presidencia semestral a las delegaciones de la Unión «conllevaría una degradación de esa representación, al ser asumida no por un miembro de pleno derecho sino por un observador», lo que ha sucedido en el seno de la Asamblea General de las Naciones Unidas, como examinaremos más adelante. Vid. DASTIS QUECEDO, A., «La diplomacia tras el Tratado de Lisboa» en Innovación y Conocimiento, op. cit. nota 15, p. 413.

${ }^{18}$ La decisión de la Unión Europea de escindir en dos su representación diplomática acreditada ante las organizaciones internacionales en Ginebra copia la solución encontrada por otros sujetos de Derecho internacional relevantes - los EE.UU., China, Canadá, India, Australia o Brasil, por ejemplo-que cuentan ya con dos misiones separadas para representar sus intereses en Ginebra, en la OMC y en las NU, con el objeto de lograr una mayor efectividad.

Con anterioridad, la Delegación de la Comisión en Ginebra ha contado con tres secciones: una, para la OMC y los asuntos económicos y comerciales conexos, otra, para asuntos de las NU, y una tercera sección común para cuestiones administrativas. Cfr. la Comunicación de la Comisión al Consejo y al Parlamento Europeo. Establecimiento de una Delegación de la UE ante las Naciones Unidas en Ginebra, Bruselas, 26.05.2010, COM (2010) 287 final. 
Jefe de la Delegación de la UE en la OMC, que debe mantenerse al nivel más alto de Embajador - equivalente al de sus homólogos - en un ámbito en que la UE tiene competencia exclusiva. Ahora bien, esta iniciativa tendrá que superar el complicado escollo de realizarse con los medios y las capacidades existentes, lo que no resultará sencillo ${ }^{19}$.

8. Otro cambio operado en la estructura organizativa interna es el relativo a la fusión de las Oficinas de Enlace de la Secretaría General del Consejo acreditadas ante organizaciones internacionales en Nueva York y en Ginebra con las Delegaciones de la Unión en estas ciudades. Estas Oficinas de Enlace, hasta la entrada en vigor del Tratado de Lisboa, funcionaban de forma autónoma, junto a la tradicional Delegación de la Comi$\operatorname{sión}^{20}$. Así, en concreto, funcionarios de la Oficina de Enlace ubicada en Nueva York señalaban que dicha fusión se había producido en un primer momento de manera informal, convirtiéndose el antiguo Jefe de la Oficina de la Secretaría General del Consejo - el Embajador Serrano- en Jefe de la Delegación de la Unión acreditada ante las NU y sita en los EE.UU., gracias a sendas cartas procedentes de los servicios pertinentes de la Comisión Europea y de la Secretaría del Consejo, así como al plácet recibido por parte de las NU.

\section{La sustitución de la CE por la UE}

9. Coincidiendo con la entrada en vigor del Tratado de Lisboa, las numerosas organizaciones internacionales en las que la antigua Comunidad Europea participaba en grados diversos - como observador o miembro, fundamentalmente - , comenzaron a sustituir las referencias en las que aparecía la «Comunidad Europea» por la «Unión Europea». Estos cambios

19 En concreto, el puesto del segundo Jefe de Delegación se creará amortizando el puesto existente de Jefe de Delegación Adjunto, suprimiendo, por tanto, temporalmente los de adjuntos. Las dos Delegaciones de la Unión en Ginebra acreditadas ante organizaciones internacionales compartirán locales y una misma administración, medida que repercutirá positivamente en su coordinación, así como en el control de gastos. Cfr. PÉREZ BERNÁRDEZ, C., «La innovación diplomática del SEAE: Una visión desde el Derecho de la puesta en marcha de las nuevas Delegaciones de la Unión Europea» en Actas del Encuentro sobre el Servicio Europeo de Acción Exterior: La Diplomacia Común Europea, Universidad Internacional Menéndez Pelayo (UIMP), Santander, 8 de septiembre de 2010 (pendiente de publicación).

${ }^{20}$ La unificación en las «delegaciones de la Unión» de las antiguas delegaciones de la Comisión y las oficinas de enlace de la Secretaría General del Consejo de la UE acreditadas ante organizaciones internacionales, constituye una medida positiva que redunda, en el plano interno, en el trabajo más próximo, no compartimentalizado, gestando una «cultura operativa común» y en el plano externo, en una mejor comprensión por parte de terceros - Estados y organizaciones internacionales - sobre el modelo de representación de la Unión, más similar al estatal. 
son visibles, por ejemplo, en los listados que los documentos de trabajo de las organizaciones internacionales incluyen al final, enumerando las representaciones participantes en las reuniones celebradas, así como en las placas identificativas de las representaciones que acuden a las mismas.

No obstante, desde la creación de la UE con el Tratado de Maastricht en 1992 se ha ido produciendo de forma paulatina una inserción de la UE de facto en el seno de las organizaciones internacionales, a medida que maduraba su personalidad jurídica internacional in statu nascendi. De esta forma, desde hace más de una década, las representaciones de la Comunidad Europea trataban, en ocasiones, cuestiones que iban más allá del antiguo pilar comunitario, valiéndose de su propia subjetividad jurídica internacional, consolidando soterradamente la personalidad de la UE, con actuaciones enmarañadas junto a los Estados miembros de la UE en los antiguos pilares segundo y tercero. Esta situación, que aparecía, por ejemplo, en el seno de las Naciones Unidas - en la Asamblea General y en el Consejo de Seguridad-, de la OTAN, de la OSCE, del Consejo de Europea, de la OIT o de la antigua Unión Europea Occidental (UEO), generaba una enorme confusión interna - dentro de las instituciones de la UE y entre sus Estados miembros - y externa - entre terceros Estados y organizaciones internacionales-.

10. La Presidencia sueca del Consejo de la Unión, en el segundo semestre de 2009, llevó a cabo una campaña de información dirigida a diversas organizaciones internacionales, informando, en cartas explicativas, con un modelo que incluía mínimas variaciones dependiendo del organismo al que iba dirigido, de las novedades que se iban a producir o se estaban produciendo en el seno de la UE. Dichas cartas incluían adjunta una notificación conjunta del Consejo de la UE y de la Comisión, en la que, además de comunicar la fecha de entrada en vigor del Tratado de Lisboa y la consecuencia principal relativa a la sustitución y sucesión de la Comunidad Europea por la Unión Europea desde aquel momento, indicaban, de forma más concreta que, «desde esa fecha la UE ejercerá todos los derechos y asumirá todas las obligaciones de la Comunidad Europea, incluyendo su status en la Organización, continuando el ejercicio de los derechos existentes y la asunción de las obligaciones por la UE».

Con una intención clarificadora, el TUE y las citadas notificaciones de la UE a organizaciones internacionales parecen mantener un principio de sucesión a favor de la nueva UE, en el que ésta se hará cargo de todos los derechos y obligaciones de las dos predecesoras - la CE y la antigua UE $-{ }^{21}$.

21 Así, en el seno de las NU, pasarían a la nueva UE los derechos relativos al estatuto de observador de la CE en algunos órganos principales de las Naciones Unidas - como la Asamblea General o el Consejo Económico y Social-, así como las prerrogativas concedidas a la Presidencia o al representante de la PESC de ser invitado a expresar la posición la Unión ante 
Ahora bien, si analizamos más detenidamente este proceso y lo comparamos con otros - v.g., el de la CECA a la CE en 2002 o el de la Unión Europea Occidental (UEO) a la UE, entre otros - la sustitución de la CE por la Unión muestra, más que un típico caso de sucesión entre organizaciones internacionales, un supuesto de «continuación» por parte de la UE de la CE y la anterior UE.

Otro aspecto de singular relevancia que recoge la notificación conjunta del Consejo y de la Comisión citada se refiere a los acuerdos concluidos en el marco de la Organización en cuestión, indicando que, «en particular, desde aquella fecha (1 de diciembre de 2009), la UE sucederá en todos los acuerdos concluidos y todos los compromisos u obligaciones adoptados en el seno de la Organización y vinculantes para la Comunidad Europea ${ }^{22}$.

Las cartas enviadas por la UE, inter alia, a las Naciones Unidas y a la OSCE, informando de las consecuencias de la entrada en vigor del Tratado de Lisboa, dejan entrever que las modificaciones operadas en la UE - con la intención de mejorar su funcionamiento y contribuir mejor a los objetivos de dichas Organizaciones - incidirían de forma diversa en éstas y que serían, por ello, informadas más adelante de las novedades al respecto ${ }^{23}$.

el Consejo de Seguridad de las Naciones Unidas, que son actualmente revisadas y actualizadas. Cfr. HAMONIC, A., L'Union Européenne à l'ONU. Perspectives ouvertes par le Traité constitutionnel, Éditions Apogée, Rennes, 2007, p. 66.

22 Council of European Union, Commission of the European Communities, Notification, Entry into force of the Lisbon Treaty, Brussels, 27 November 2009, en www.delvie.ec.europa.eu

23 Así, por ejemplo, en relación a las organizaciones internacionales y otros organismos vinculados a las Naciones Unidas con sede en Viena, el Embajador de la Representación Permanente de Suecia ante las Naciones Unidas y el Jefe de la Delegación de la UE acreditada ante las organizaciones internaciones con sede en la capital austriaca envían conjuntamente una carta informativa dirigida a todas las representaciones permanentes y observadores ante las organismos de las Naciones Unidas en dicha ciudad. En dicha comunicación indican que el 1 de diciembre de 2009 - fecha en la que fue redactada la carta - ha entrado en vigor para la UE el Tratado de Lisboa. La carta explica que el objetivo de este nuevo Tratado es mejorar las formas de trabajo de la UE, incidiendo en que ésta tenga una voz más clara y sólida en el mundo, además de hacerla más democrática, eficiente y transparente. El escrito incluye también que se han producido algunos cambios en los modos de tomar decisiones en la UE, así como en la representación externa. En este punto se señala que tiene una importancia particular para el sistema de las Naciones Unidas la designación de la Sra. Catherine Ashton como Alta Representante de la Unión para Asuntos Exteriores y Política de Seguridad y Vicepresidenta de la Comisión Europea. La carta indica que, un nuevo órgano se ha establecido, el Servicio Europeo de Acción Exterior (SEAE), que asistirá a la Alta Representante en el cumplimiento de su mandato. Se refiere a la composición variada del SEAE, a la inclusión de las delegaciones de la UE en dicho Servicio, que representan a la Unión ante terceros Estados y organizaciones internacionales. Expresamente indica el cambio de denominación de la Delegación de la Comisión Europea a la Unión Europea desde la fecha de entrada en vigor del Tratado de Lisboa, lo que conllevará cambios en la representación que serán comunicados a medida que se vayan produciendo. El escrito finaliza indicando que si 
La situación anteriormente descrita pone de relieve que la UE deja abierta brechas en la mayoría de las organizaciones internacionales en las que participa y que dependiendo del grado de flexibilidad de las reglas de éstas, de la buena voluntad de los miembros de dichas organizaciones y del buen hacer de la propia Unión y de sus Estados miembros, los acomodos que tiene que acometer la UE, y que se encuentran en marcha, le resultarán más o menos complejos.

\section{La compleja consolidación de un estatuto privilegiado para la UE en la Asamblea General de las Naciones Unidas en el contexto del SEAE}

11. Al hilo del discurso mantenido anteriormente, resultan de especial interés los últimos movimientos que están teniendo lugar en el seno de las Naciones Unidas por parte de la UE - consecuencia de las novedades introducidas por el Tratado de Lisboa y de la puesta en marcha del SEAE-. La situación se refiere, más concretamente, a la participación más activa de la Unión en el órgano plenario de esta Organización Internacional, la Asamblea General de las Naciones Unidas (AGNU). Las iniciativas más recientes por parte de la UE en este sentido - presentadas al final del 64 . $^{\circ}$ periodo ordinario de sesiones de la AGNU, en septiembre de de 2010 - no han prosperado. Dicho resultado ha sido interpretado mayoritariamente como un fracaso de la UE, causando cierta frustración en determinados círculos por no haber conseguido una representación más sólida ante las Naciones Unidas. A mayor abundamiento, se ha mantenido, incluso, que desde la entrada en vigor del Tratado de Lisboa, en vez de avanzar, se ha retrocedido en cuanto a la representación de la UE en el exterior ${ }^{24}$.

\footnotetext{
bien, en lo que resta de 2009 no se realizará ningún otro cambio en el contexto de las Naciones Unidas, en breve remitirán nueva información a todas las organizaciones internacionales y misiones permanentes sobre medidas que puedan afectarles derivadas de la implementación del Tratado de Lisboa. Cfr. Swedish Presidency of the European Union, Entry into force of the Lisbon Treaty, To: All Permanent Representatives and Observers to the UN Organisations in Vienna, December 1, 2009; Cfr. Swedish Presidency of the European Union, Entry into force of the Lisbon Treaty, To: H.E. Mara Marinaki, Ambassador, Permanent Representative to Greece to the OSCE, CIO.GAL/183/09. Ambos documentos pueden encontrarse la página de la delegación de la UE acreditada ante distintas organizaciones internacionales con sede en Viena, www.delvie.ec.europa.eu

${ }^{24}$ Con esta visión derrotista se hicieron eco distintos medios de comunicación en septiembre de 2010. Cfr., inter alia, «La UE fracasa en su intento de hablar con voz propia en la ONU», El Mundo, 14-09-2010; «Fracasa la UE en búsqueda de prerrogativas dentro de la Asamblea General de las ONU», Vanguardia, www.vanguardia.co.cu
} 
12. Para entender los elementos de esta situación, explicaré en qué estado se encuentra la participación de la UE en organizaciones internacionales (1.); con una mirada atrás, daré cuenta de los antecedentes de la UE y de sus Estados miembros en el seno de Asamblea General de las Naciones Unidas (2.), y, por último, examinaré el momento presente, las iniciativas adoptadas por la UE con la finalidad consolidar un estatuto privilegiado en la AGNU (3.), exponiendo mi postura, más optimista y comprensiva con el resultado de los acontecimientos, que debe contextualizarse teniendo presentes las aspiraciones de distintos Estados, entre ellos, ciertas potencias emergentes, que desean lograr una representación más sólida en la ONU; contrastando esta reivindicación de los Estados emergentes, con el actual estado de «sobre representación» de la UE que estos países hacen valer y que ha influido en el rechazo de las pretensiones de la UE durante el periodo de sesiones $64 .^{\circ}$.

\section{El punto de partida: La participación de la UE en organizaciones internacionales}

13. La UE se encuentra inmersa en un proceso de modificación de sus formas de representación externa, con importantes implicaciones en la articulación de su participación en foros universales bien heterogéneos, lo que es consecuencia del Tratado de Lisboa y de la reestructuración llevada a cabo por el SEAE. Una de las mayores dificultades que la UE encuentra, se refiere a que el papel que desempeña en cada organización internacional no depende exclusivamente de lo que ella desea, sino de lo que acuerden y acepten la organización en cuestión - y soterradamente en ella, sus Estados miembros - , por un lado, y la UE - y sus respectivos Estados-, por otro $^{25}$, como tendremos la oportunidad de comprobar en el caso de análisis incluido en los dos siguientes apartados (2. y 3.).

El objeto de este apartado es esbozar, a grandes rasgos, los contenidos esenciales relativos a la participación de la Unión en organizaciones internacionales, incluyendo los derechos básicos a los estatutos de observador y miembro, pasando por el reforzamiento de la condición de observador en numerosos organismos; dentro de este repaso, que nos ayudará a situar ade-

25 Efectivamente, pese a que una característica esencial de las organizaciones internacionales sea su autonomía jurídica respecto de los Estados que la componen, más de tres décadas después, continúan estando vigente las palabras de DUPUY, en relación con su transparencia, según las cuales: «En dépit de son autonomie juridique, elle laise voir les Etats toujours présents derrièrre ses structures», DUPUY, R.-J., Le droit International, $5^{\mathrm{e}}$ Edition, Ciudad, Que Sais-Je?, n. ${ }^{\circ}$ 1060, 1976, p. 121. 
cuadamente los desarrollos posteriores ligados a la Asamblea General de las Naciones Unidas, incorporo ejemplos de las categorías citadas y realizo un repaso a la regulación jurídica sobre la materia en el Derecho primario.

14. Junto al ejercicio del derecho de legación activo y pasivo de la Unión Europea en organizaciones internacionales y la cooperación y coordinación de carácter administrativo formalizada a través de acuerdos de trabajo, es la participación de la UE en organizaciones internacionales la forma más avanzada que pueden adquirir las relaciones de la UE con estos sujetos secundarios de Derecho internacional. Dicha participación puede desarrollarse con estatutos diversos, siendo los más comunes, el de observador, que constituye la condición típica y más frecuente de actuación de unas organizaciones internacionales en otras, y el de miembro, que conlleva una vinculación mucho más profunda y compleja, y que es utilizada principalmente por los Estados ${ }^{26}$.

De forma sintética y obviando los múltiples matices propios de cada organización internacional, el contenido de los dos estatutos típicos, incluye,

${ }^{26}$ La dedicación dada por la doctrina a la participación de la UE en organizaciones internacionales ha sido menor si comparamos este sector con otros de la acción exterior de la UE. Una representación de las obras y artículos dedicados a este ámbito son los siguientes: una obra esencialmente jurídica y completa, con detallados ejemplos de participación, puede consultarse en FRID, R., The Relations Between the EC and International Organizations. Legal Theory and Practice, Kluwer International Law, The Hague, 1995; en la doctrina española destaca, como uno de los primeros trabajos ad hoc sobre la materia, el jugoso artículo de ROLDÁN BARBERO, J., «La Participación de la Unión Europea en Organismos Internacionales» en MARIÑO MENÉNDEZ, F.M. (ed.), Acción Exterior de la Unión Europea y Comunidad Internacional, Universidad Carlos III de Madrid, Boletín Oficial del Estados, Madrid, 1998, pp. 243-271; un claro resumen de la situación, que incluye unos breves casos de análisis seleccionados, puede encontrarse en ANDRÉS SÁENZ DE SANTA MARÍA, P., «La Unión Europea en el Concierto de las Organizaciones Internacionales» en $R D C E, \mathrm{n}^{\circ}{ }^{\circ} 3,2 .^{\circ}$ semestre 2002, pp. 121-142; las dos monografías de la doctrina española dedicadas a esta cuestión, son las de PÉREZ BERNÁRDEZ, C., Las relaciones de la Unión Europea con Organizaciones Internacionales, op. cit., nota 3, y SANTOS VARA, J., La Participación de la Unión Europea en las Organizaciones Internacionales, Colex, Madrid, 2002; dentro de los manuales españoles destaca el tratamiento de la cuestión dado por MANGAS MARTíN, A. y LIÑÁN NOGUERAS, D.J., Instituciones y Derecho de la Unión Europea, Tecnos, 6. ${ }^{a}$ edición, Madrid, 2010, pp. 514-517; asimismo, SÁNCHEZ, V. (ed.), Instituciones de la Unión Europea, Huygens, 2010, pp. 270-272; con una estructura de análisis más tradicional y esencialmente jurídica, GOVAERE, I., CAPIAU, J., VERMEERSCH, A., «In-Between Seats: The Participation of the European Union in International Organizations» en European Foreign Affairs Review 9, 2004, pp. 155-187; uno de los trabajos más recientes, con una perspectiva analítica más amplia pueden encontrarse en GSTÖHL, S., «"Patchwork Power” Europe: The EU's Representation in Internacional Institutions» en European Foreing Affairs Review, 14, 2009, pp. 385-403; otra aportación reciente puede encontrarse en HOFFMEISTER, F., «Outsider or Frontrunner? Recent Developments under International and European Law on the Status of the European Union in International Organizations and Treaty Bodies» en CMLR, 2007, 44/1, pp. 41-68. 
a grandes rasgos, los siguientes derechos. En primer lugar, el estatuto de miembro permite disfrutar del derecho de voto, esencial en el proceso de adopción de decisiones, así como el derecho de presencia y de expresión en los órganos de las organizaciones internacionales, de acuerdo con lo establecido por las reglas de la organización en cuestión. El estatuto de observador, por el contrario, no da derecho a disponer de voto, mientras que su presencia y uso de la palabra se encuentran mucho más limitados.

15. El estatuto de miembro para la UE en las organizaciones internacionales no es sencillo de lograr porque debe contar con el visto bueno del organismo en cuestión - y, por ende, de los Estados miembros que lo componen-, que en muchos casos no dispone de una normativa adaptada para la actuación en su seno de una entidad distinta a los Estados. Además, hay que tener en cuenta que, en la mayoría de los casos en que la UE participa como miembro en una organización internacional, lo hace conjuntamente con sus Estados miembros, ya que éstos continúan manteniendo importantes competencias en el ámbito de actividad de dicha organización ${ }^{27}$.

Las dificultades de diversa índole que obstaculizan la partipación de la UE en calidad de miembro en organizaciones internacionales, han propiciado que la Unión mantenga un estatuto de observador privilegiado u otra representación destacada que le permita desenvolverse más fácilmente en los trabajos de la organización en cuestión, pese a no contar con el estatuto formal de miembro. Estas situaciones, transitorias en algunos casos, tienen

${ }^{27}$ Las complicaciones derivadas la participación conjunta de la UE y de sus Estados miembros en una organización internacional, en términos de votación, derecho de expresión, contribución al presupuesto de la organización, etc. son resueltas, no sin dificultades, a través de medios diversos, dependiendo de la organización. Ejemplos de organizaciones internacionales en las que la UE participa como miembro con sus Estados miembros son, inter alia, la FAO, la OMC, la Autoridad Internacional de los Fondos Marinos, el Banco Europeo de Reconstrucción y Desarrollo, ciertas organizaciones que se ocupan de gestionar productos de base y materias primas, como la Organización Internacional del Café, la Organización Internacional del Cacao, la Organización Internacional del Yute o la Organización Internacional de las Maderas Tropicales.

Habida cuenta de sus competencias exclusivas en la materia tratada por la organización, la UE ha conseguido participar de forma exclusiva - esto es, sin sus Estados miembros - por ejemplo, en numerosos organismos de carácter técnico establecidos en virtud de acuerdos internacionales, como los que se ocupan de las pesquerías, por ejemplo, la Organización de Pesquerías del Atlántico Noroeste (OPANO), la Comisión de Pesquerías del Atlántico Nordeste (CPANE), la Organización para la Conservación del Salmón del Atlántico (OCSAN) o la Comisión Internacional para la Conservación de los del Atún del Atlántico (CICAA); también mantiene su participación de miembro exclusivo en otras organizaciones administradoras productos básicos, como el Consejo Oleícola Internacional o el Consejo Internacional del Azúcar. 
como objetivo allanar el camino para alcanzar el estatuto de miembro ${ }^{28}$. La intensidad con la que UE acometa la tarea de reivindicar la condición de miembro y el ejercicio de los derechos vinculados a su actuación en la organización dependerán, en gran medida, del alcance y de la naturaleza mixta o exclusiva de sus competencias, teniendo en cuenta el ámbito de trabajo de la organización en cuestión.

16. La escasa regulación jurídica que el Derecho primario de la UE dedica a las relaciones de la UE con organizaciones internacionales llama especialmente la atención, por el contraste que existe si tenemos en cuenta el amplio grado de desarrollo que dichas relaciones han alcanzado. Las mejoras en este ámbito no se han producido con el Tratado de Lisboa, al no incluir una disposición general que, de forma expresa, prevea la participación de la Unión en organizaciones internacionales ${ }^{29}$. El Tratado de Lisboa se limita a modificar mínimamente la disposición principal del Derecho primario dedicada a la cuestión, esto es, el artículo 220 TFUE, fusionando con variaciones menores los antiguos artículos 302 a 304 TCE-30.

Como novedades, esta disposición incluye acertadamente, respecto a la versión anterior, a la OSCE, entre el grupo privilegiado de organismos con los que la UE mantiene vínculos estrechos de participación. Asímismo, la responsabilidad de la Comisión Europea de asegurar el mantenimiento de relaciones con organizaciones internacionales (que recogía el antiguo

28 Así, antes de que la UE (anteriormente CEE o CE) se adhiriera en calidad de miembro a algunas organizaciones internacionales, disfrutó del modesto estatuto de observador, por ejemplo, en la FAO o en EUROCONTROL. Son muy numerosos los ejemplos de participación de la UE en calidad de observador. Como en las dos últimas décadas la UE se ha visto beneficiada por la concesión de alguna prerrogativa, habida cuenta de sus especificidades, dicho estatuto puede ser calificado más adecuadamente como de observador privilegiado, inter alia, en organismos especializados de las Naciones Unidas como el Fondo Monetario Internacional (FMI), la OMPI, la OMS, la OIT o el Banco Internacional de Reconstrucción y Desarrollo (BIRD); en órganos subsidiarios de las Naciones Unidas como el PNUMA, la Conferencia de las Naciones Unidas para el Comercio y el Desarrollo (UNCTAD) o el Alto Comisionado de las Naciones Unidas para los Refugiados (ACNUR); en otros organismos ajenos al sistema de las Naciones Unidas, como la OTAN, la Organización Mundial de Aduanas, la OSCE, la Organización para la Aviación Civil Internacional (OACI); en el Consejo de Europa y en la OCDE, el estatuto de observador reforzado de la UE suele denominarse de «participante en los trabajos».

${ }^{29}$ Existe, no obstante, una referencia específica al respecto en el ámbito de la unión económica y monetaria (art. 138 TFUE).

${ }^{30} \mathrm{El}$ artículo 220 TFUE reza: $1 .^{\circ}$ «La Unión establecerá todo tipo de cooperación adecuada con los órganos de las Naciones Unidas y de sus organismos especializados, el Consejo de Europa, la OSCE y la OCDE.

La Unión mantendrá también relaciones apropiadas con otras organizaciones internacionales.

2. ${ }^{\circ}$ El Alto Representante de la Unión para Asuntos Exteriores y Política de Seguridad y la Comisión se encargarán de aplicar lo dispuesto en el presente artículo». 
art. 320 TCE) sigue vigente, si bien, ahora, es compartido con el nuevo Alto Representante - que es también Vicepresidente de la Comisión-, dando un protagonismo más amplio a toda la UE, como indica el artículo 220.2. ${ }^{\circ}$ TFUE. Así, la actual Alta Representante, asistida por el SEAE (art. 27.3. ${ }^{\circ} \mathrm{TUE}$ ), pasa a desarrollar funciones claves en las organizaciones internacionales y otros foros, representando a la UE en el exterior, dirigiendo el diálogo con terceros y expresando la posición de la Unión en organizaciones y conferencias internacionales (arts. 27.2. ${ }^{\circ}$ TUE); también ante el Consejo de Seguridad de las Naciones Unidas, si bien, dicho derecho de expresión queda supeditado a la previa petición de los Estados miembros de la Unión que lo sean de dicho órgano y a la autorización del propio Consejo de Seguridad (art. 34 in fine TUE, cfr. nota 35). El Alto Representante contribuye con sus propuestas a elaborar la PESC (art. 27.1. ${ }^{\circ}$ TUE), organiza la coordinación de los Estados miembros para defender las posiciones de la Unión en organizaciones y conferencias internacionales (art. 34.1. ${ }^{\circ}$ TUE) y, en definitiva, asiste a la Comisión y al Consejo a garantizar la coherencia y la buena coordinación de la actuación exterior de la Unión (art. 21 in fine TUE).

17. En el Derecho primario, el grueso de las referencias relativas al establecimiento de vínculos entre la UE y las organizaciones internacionales aparece desordenado y se dedica fundamentalmente al ius ad tractatum, confiriéndole a la UE la competencia expresa para celebrar tratados internacionales con organizaciones internacionales en ámbitos muy diver$\operatorname{sos}^{31}$.

Ahora bien, la práctica que la UE ha generado en materia convencional y en sus relaciones con organizaciones internacionales no tiene parangón si la comparamos con cualquier otro sujeto secundario de Derecho internacional. El artículo 220 TFUE (y sus versiones anteriores) ha servido de fundamento jurídico de una vastísima cooperación administrativa con prácticamente todas las organizaciones internacionales. Esta disposición,

${ }^{31}$ La falta de sistemática en este ámbito no ha sido corregida por el Tratado de Lisboa, que recoge de forma desordenada en el TFUE las competencias exteriores expresas de la Unión en diversos ámbitos, heredando, en la mayoría de los casos, fórmulas de versiones del Tratado constitutivo pasadas. Así, la fórmula generalmente utilizada señala que la Unión cooperará y celebrará acuerdos con terceros países y organizaciones internacionales en distintos ámbitos, como el de la investigación y desarrollo tecnológico (art. 186 TFUE), el medio ambiente (art. 191.4. ${ }^{\circ}$ TFUE), el de la educación y el deporte (arts. 165.3. ${ }^{\circ}$, citando expresamente al Consejo de Europea), en materia de formación profesional (166.3. ${ }^{\circ}$ TFUE), en cultura (art. 167 TFUE, incluyendo de nuevo al Consejo de Europa), en el ámbito de la salud pública (art. 168.3. ${ }^{\circ}$ TFUE), de la cooperación al desarrollo (arts. 208 y 209.2. ${ }^{\circ}$ TFUE, que menciona expresamente a las Naciones Unidas), en el ámbito de la cooperación económica, financiera y técnica con terceros (art. 212.3. ${ }^{\circ}$ TFUE) y en el ámbito de la ayuda humanitaria -introducido por el Tratado de Lisboa - (art. 214.4. ${ }^{\circ}$ y $7 .^{\circ}$ TFUE, que cita expresamente a las Naciones Unidas), entre otros. 
por vía implícita, a coadyuvado al desarrollo del derecho de legación y de participación con estatutos diversos. Ahora bien, la regulación insuficiente y las lagunas cada vez más presentes obligaron al Tribunal de Justicia de la UE (entonces TJCE) a pronunciarse en repetidas ocasiones, reconociendo las competencias implícitas. De forma temprana - desde el célebre asunto AETR - el TJUE ha desarrollado un papel clave, abriendo la vía del paralelismo entre las competencias internas y externas, con la posibilidad concreta de la UE - antes CE - de adherirse o establecer convenios constitutivos de organizaciones internacionales - asunto de la navegación por el Rin- ${ }^{32}$.

En último término, ante la inexistencia de competencias expresas o implícitas, queda la vía subsidiaria del artículo 352 TFUE (ex art. 308 TCE), que a modo de cláusula de imprevisión, también se ha utilizado como base jurídica complementaria para que la UE pudiera participar con el estatuto de miembro en determinadas organizaciones internacionales ${ }^{33}$.

\section{Antecedentes: La UE en la Asamblea General de las Naciones Unidas}

18. La AGNU, por las características inherentes a su composición, constituye el órgano que mejor «toma el pulso» a la sociedad internacional, poniendo de relieve sus debilidades, consensos y desafíos. En este órgano están presentes los 192 Estados actualmente miembros de las Naciones Unidas, contando cada uno de ellos con un voto ${ }^{34}$.

En 1945, en la Conferencia de San Francisco se estableció que podrían ser Miembros de las Naciones Unidas, los «Estados amantes de la paz que acepten las obligaciones consignadas en la Carta» (art. 4 Carta de las NU). Dicha fórmula, según la cual se permitía el ingreso en esta Organización Internacional de vocación universal y fines generales, únicamente a Estados - como sujetos de Derecho internacional - era acorde con la estructura interestatal que presidía de forma acusada la sociedad internacional de la posguerra. La condición estatal representa la condición esencial para poder ser, a su vez, miembro de la Asamblea General de las Naciones Unidas (art. 9.1. ${ }^{\circ}$ Carta de las NU).

19. Por otro lado, a medida que el proceso de integración europeo ha ido evolucionando y sus ámbitos competenciales ampliándose a nuevos sectores tratados en el seno de las Naciones Unidas, la UE (antes la CE y pre-

32 Cfr. asunto 22/70, Comisión/Consejo, AETR, loc. cit., nota 2, pp. 263 y ss.; Dictamen 1/76 del TJCE, de 26 de abril de 1977, sobre el proyecto de acuerdo para el establecimiento de un Fondo europeo de inmovilización de la navegación interior, Rec. 1977, pp. 741 y ss.

33 Por ejemplo, en la FAO, la OMC y en el BERD.

${ }^{34}$ Cfr. artículo 18.1. ${ }^{\circ}$ de la Carta de las Naciones Unidas. 
viamente la Comunidad Económica Europea - CEE - ) y sus Estados miembros no han sido capaces de modificar las «reglas del juego» de las Naciones Unidas inicialmente establecidas en materia de adhesión, en el sentido de permitir que «otras entidades u organizaciones de integración regional» pudieran participar en la misma en calidad de miembro, manteniéndose, aún en el caso de ingreso de la Unión, el estatuto actual de miembro para los países integrantes de la Unión ${ }^{35}$. Dicha permanencia de la condición de miembro de las Naciones Unidas para los Estados miembros de la UE sería, en todo caso, obligada en el estadio actual, ya que éstos continúan teniendo competencias que no han sido cedidas a la UE en ámbitos en los que las Naciones Unidas desarrolla sus funciones. Este argumento llevó a que, cuando la entonces

35 Tampoco el conjunto de los Estados miembros de la UE ha conseguido una posición única sobre los cambios que, desde la Unión, sería deseable acometer en relación a una nueva y actualizada composición del Consejo de Seguridad de las Naciones Unidas, habida cuenta de las especiales sensibilidades de Reino Unido y Francia, los dos integrantes de la Unión con estatuto de miembros permanentes en este órgano. El debate abierto gira en torno a la posibilidad de que la UE se convirtiera en miembro permanente, si bien se presentan aspectos complejos, relativos, por ejemplo, al peso en las votaciones en caso de que se produjera una sustitución por aquellos dos países o al posible mantenimiento del estatuto privilegiado de Reino Unido y Francia complementado con un estatuto permanente «descafeinado» para la Unión, que careciera de derecho de veto.

En este contexto, el TUE incluye en el artículo 34.2. ${ }^{\circ}$ ciertas reglas relativas al suministro de información y a la defensa de las posiciones e intereses de la Unión por parte de los Estados miembros que también lo fueran del Consejo de Seguridad de las Naciones Unidas, incluyendo la obligación de mantener al tanto al resto de los miembros de la Unión y al Alto Representante de la Unión para Asuntos Exteriores y Política de Seguridad, de acuerdo con lo establecido en el Tratado de Lisboa Ahora bien, dichos cometidos se realizarán - con la inclusión de la debilitante fórmula-: «sin perjuicio de las responsabilidades que les incumban en virtud de las disposiciones de la Carta de las Naciones Unidas». En la práctica, las consultas establecidas en el actual artículo 34 TUE (ex art. 19) tienen lugar una vez a la semana a dos niveles, de Jefes de Misión y de expertos responsables de los asuntos tratados en el Consejo de Seguridad de las Naciones Unidas. Dichas reuniones han ido evolucionando en el sentido de hacerse más activas y abiertas, de forma que los otros Estados miembros de la Unión no participantes en el Consejo de Seguridad intervienen dando su opinión sobre los temas que se encuentran bajo su consideración, a través de un debate que se aleja de una mera recepción de información sobre las deliberaciones en el seno de este órgano político restringido. Cfr. HAMONIC, A., op. cit., nota 21, pp. 86 y ss.; KNUDSEN, M., The EU, the UN and Effective Multilateralism: The case of UN reform, Institute of European Studies, en www.ies.be, pp. 1-15, en concreto, p. 4; LUIF, P., RADEVA, M., «EU Co-ordination in International Organizations: The Case of the United Nations General Assembly and the Organization for Security and Co-operation in Europe» en CASARINI, C., MUSU, C. (eds.), European Foreign Policy in an Evolving International System: The Road towards Convergence, Palgrave Macmillan, Basingstoke, 2007, pp. 27-40 y pp. 34-38; VERBEKE, J., «EU Coordination on UN Security Council Matters» en WOUTERS, J., HOFFMEISTER, F., RUYS, T. (eds.), The United Nations and the European Union: An Ever Stronger Partnership, T.M.C. Asser, The Hague, 2006, pp. 49-62. 
CEE se adhiriera a la FAO en 1991 en calidad de miembro, se mantuviera la participación de sus Estados miembros. Dicho acceso fue posible gracias al consenso de las partes implicadas, la propia FAO, la UE y sus respectivos Estados miembros. No es una decisión que pueda decidir unilateralmente ninguna de ellas, ya que los acomodos a realizar son complejos ${ }^{36}$.

20. En la Asamblea General de las Naciones Unidas, la - entoncesCEE consiguió el estatuto de observador, en virtud de la Resolución 3208 (XXIX), adoptada sin votación el 11 de octubre de 1974. En ella se solicitaba al Secretario General de las NU que invitara a la CEE en calidad de observadora a participar en las sesiones y trabajos de la Asamblea General ${ }^{37}$.

La UE se ha ido aprovechando en la AGNU - y en tantos otros organismos internacionales - de la vía indirecta del estatuto de «miembro» del que disfrutan sus propios Estados miembros. En el caso de la AGNU, mientras que la representación de la UE en las seis comisiones principales ha sido más flexible - destacando su actuación en la segunda, dedicada a cuestiones económicas y financieras - , le resulta mucho más limitada en la formación plenaria, en donde su consideración de participante con carácter restringido la mantiene más encorsetada. Ahora bien, la UE ha aprovechado en el plenario esta membresía de sus Estados miembros, en concreto, la del país que preside el Consejo de la Unión en dicho semestre, obviando así la

36 Vid. sobre el progresista proceso de modificación de la Constitución de la FAO gracias al cual se permitió el acceso a la UE en calidad de organización de integración económica regional, DE PASCALE, R., «L'Ammisione della CEE alla FAO, Cronaca di un Negoziato» en La Comunitá Internazionale, vol. 47, 1992, pp. 477-492; FRID, R., «The European Economic Communiy. A Member of a Specialized Agency of the United Natiosn» en EJIL, 1993, pp. 239-255; PÉREZ BERNÁRDEZ, C., Las relaciones de la Unión Europea con Organizaciones Internacionales, op. cit., nota 3, pp. 518-545; PONS RAFOLS, F.-X., «La admisión de la Comunidad Económica Europea como miembro de la Organización de las Naciones Unidas para la Agricultura y la Alimentación» en RIE, vol. 21, 1994-2, pp. 419-456. Sobre el complejo ejercicio alternativo del derecho de votación por parte de la UE en la FAO, vid., HELISKOSKI, J., «Internal Struggle for International Presence: The Exercise of Voting Rights within the FAO» en DASHWOOD, A., HILLION, C. (eds.), The General Law of E.C. External Relations, Sweett \& Maxwell, London, 2000, pp. 79-99; asunto C-25/94, Comisión c. Consejo, Sentencia del TJCE de 19 de marzo de 1996, Rec. 1996-3, pp. I-1469-1512.

37 El hecho de que en la misma fecha en la que se otorgó a la CEE el status de observador, se concediera ese mismo estatuto, que contiene una participación restringida extremadamente limitada, a otros entes con subjetividad jurídico-internacional restringida, como la Organización para la Liberación de Palestina (OLP) o el Consejo de Asistencia Económico Mutuo (CAEM), muestra el propósito de la Asamblea General de no tratar de forma preferente a la UE, así como las reticencias de los Estados de la órbita soviética a aceptar la personalidad jurídica internacional de esta entidad. Además, una vez que los representantes de la OLP comenzaron a ejercer el derecho de expresión en la Asamblea General, la Comisión Europea pasó igualmente a hacer uso de este derecho, que anteriormente disfrutaba únicamente en las propias comisiones de este órgano plenario. Cfr. HAMONIC, A., op. cit., nota 21, p. 85. 
falta de derecho de expresión del observador en el Pleno de la AGNU. Esta práctica no ha sido contestada por el resto de los integrantes de las $\mathrm{NU}^{38}$. Así, durante estas últimas décadas se han ido acomodando oficiosamente las reglas de NU con una mayor representación de la UE en la AGNU ${ }^{39}$.

En la Asamblea General de las Naciones Unidas, la cooperación entre la Unión y sus Estados miembros resulta clave, ya que la mayoría de las cuestiones incluidas en la agenda de este órgano pertenecen a la competencia de ambas partes ${ }^{40}$. La coordinación entre los Estados miembros de la UE no constituye una práctica novedosa, si bien en los últimos años ha ido ocupando más tiempo y dotándose de mejores medios, logrando, de esta forma, resultados más satisfactorios ${ }^{41}$.

${ }^{38}$ Los representantes de la Presidencia rotatoria del Consejo de la Unión han utilizado en las reuniones deliberatorias de la AGNU una doble placa identificativa, una, con el nombre de su país y, otra, con el de la UE.

39 La representación de la UE en la AGNU se ha denominado bicéfala, al contar con representantes tanto de la Comisión Europea, como del Estado miembro que ejerce la Presidencia, asistidos tradicionalmente por el Secretario del Consejo de la Unión. Al hilo de lo señalado, resulta ilustrativo el ejemplo expuesto por HOFFMEISTER y KUIJPER, sobre la actuación de la UE en la $6 .{ }^{\text {a }}$ Comisión de la AGNU debatiendo sobre el informe anual de la Comisión de Derecho Internacional dedicado a la responsabilidad de las Organizaciones Internacionales, para mostrar cómo la representación de la UE es difícil de entender para terceros Estados y cómo dicha representación no se decide interna y unilateralmente - por la propia Unión - sino teniendo en cuenta las reglas oportunas de las Naciones Unidas. En el ejemplo, estos autores señalan que en dicha sesión tomó la palabra el representante de Reino Unido - que ejercía la Presidencia del Consejo en aquel momento- y, tras realizar una presentación dio paso, «con el consentimiento de los demás miembros de las Naciones Unidas», al representante de la Comisión Europea, que comenzó a exponer su declaración en nombre de la UE. Cfr. HOFFMEISTER, F., KUIJPER, P.J., «The Status of the European Union at the United Nations: Institutional Ambiguities and Political Realities», op. cit., nota 35, pp. 9-34, en concreto, pp. 9-10.

${ }^{40} \mathrm{El}$ sistema seguido de forma ordinaria intentaba calificar la materia que iba a ser objeto de debate en la Asamblea General; así, si se trataba de una cuestión de competencia comunitaria principalmente - de naturaleza exclusiva o mixta - la coordinación se llevaba a cabo en la oficina de la delegación de la Comisión (actualmente «de la UE») en Nueva York, en donde se reúnen los representantes de los Estados miembros de la Unión. Por otro lado, las cuestiones relativas a los - antiguos - pilares segundo y tercero se coordinaban a través de reuniones de las delegaciones de los Veintisiete acreditadas ante las Naciones Unidas en la misión del Estado que ejerciera la Presidencia del Consejo y en la Oficina de Enlace de la Secretaría General del Consejo de la UE ante las Naciones Unidas, así como en otros lugares, cuando no existía suficiente espacio físico para mantener diversas reuniones entre los Estados miembros.

${ }^{41}$ El incremento progresivo de las reuniones ha incidido en el aumento de los votos comunes de los Estados miembros de la UE conducentes a la adopción de resoluciones en la AGNU por consenso, que es del 95\%, y del 76\% cuando se lleva a votación - según los últimos datos-. Ello significa que, en este último supuesto, la UE vota unánimemente 4 de cada 5 resoluciones de la Asamblea General de las Naciones Unidas. De la práctica se deduce que la obtención de una postura acorde entre los miembros de la Unión es más sencilla respecto de nuevas cuestiones, debido a los efectos positivos de la disciplina de coordinación temprana, 
En definitiva, el estatuto de observador ordinario para la UE en la AGNU ha evolucionado de facto en un «observador privilegiado», que le ha permitido una actuación más flexible y completa en derechos - si la comparamos con otros observadores $-{ }^{42}$. Ciertas prácticas consolidadas, gracias al esfuerzo negociador y al satisfactorio trabajo de las representaciones de los Estados miembros y de la UE en la Asamblea General de las Naciones Unidas, han permitido dicho desenvolvimiento por parte de la Unión, pese a no contar con una nueva resolución consolidando dicho estatuto más desarrollado.

\section{Los últimos desarrollos: El proyecto de resolución sobre la «participación de la UE en la labor de las Naciones Unidas»}

21. En la última década del siglo XX y la primera del XXI, la cooperación entre las Naciones Unidas y la UE ha cobrado un mayor ímpetu, sobre todo por el desarrollo de la PESC ${ }^{43}$. No resulta, por ello, extraño que

que lleva más fácilmente a las posiciones comunes; por el contrario, las cuestiones antiguas se encuentran enmarañadas en el contexto político más complejo por las posiciones nacionales de cada Estado miembro (por ejemplo, descolonización, Oriente Medio y desarme nuclear, inter alia). Se han incrementado, así, las declaraciones comunes y explicaciones del voto en el seno de la AGNU realizadas por la Presidencia en nombre de la UE. Resulta curioso el hecho de que la Presidencia de la UE suele adoptar cientos de posiciones comunes al año ante la AGNU, mientras que la Comisión Europea presenta únicamente de 5 a 7 en ese mismo periodo. Ahora bien, la Comisión juega un papel informal destacado en las sesiones de la Asamblea General, así como en la realización de proyectos de posiciones comunes presentadas por la Presidencia. Los posicionamientos de la Unión resultan en muchas ocasiones atractivos para terceros Estados con los que mantiene relaciones privilegiadas (países asociados, candidatos a la UE o miembros de la Asociación Europea de Libre Comercio - AELC - ), alineándose frecuentemente con la postura de la UE. De hecho, la UE es la única entidad que desarrolla posiciones globales y articuladas en la AGNU sobre cada una de las cuestiones que se incluyen en el orden del día. Cfr., sobre estos temas, RASH, M.B., The European Union at the United Nations: The Functioning and Coherence of EU External Representation in a State-Centric Environment, Leiden, Martinus Nijhoff, 2008, pp. 205 y ss.; BRÜCKNER, P. «The European Community and the United Nations» en EJIL, vol. 1, n. ${ }^{\circ} 1 / 2$, 1990, pp. 174-192; COT, J.P., «La Communauté Européenne, l'Union Européenne et l'Organisation des Nations Unies» en Boutros BoutrosGhali Amicorum Discipulorumque Libera, vol. 1, Bruylant, Bruxelles, 1998, pp. 327-346; HIGGINGS, R., «The EC and the New United Nations» en European University Institute Working Paper, Robert Schuman Center, n. ${ }^{\circ}$ 94/7; FARREL, M., «EU Representation and Coordination within the United Nations» en LAATIKAINEN, K.V., SMITH, K.E. (eds.), The European Union at the United Nations: Intersecting Multilateralism, Palgrave Macmillan, Basingstoke, 2006, pp. 27-46; PAASIVIRTA, E., PORTER, D., «EU Coordination at the UN General Assembly and ECOSOC: A View from Brussels, a View from New York», op. cit., nota 35, pp. 35-48; WOUTERS, J., HOFFMEISTER, F., RUYS, T., op. cit., nota 35, pp. 385-386.

${ }^{42}$ Cfr. HAMONIC, A., op. cit., nota 21, p. 85.

43 Algún autor muestra con gran realismo y cierto desencanto que los intereses nacionales continúan constituyendo la principal fuerza que impulsa las políticas de los Estados miem- 
la Comisión Europea afirmara en 2003 que «la política exterior de la UE se define fundamentalmente por un compromiso con el multilateralismo». La cooperación internacional es la condición previa para enfrentarse a los numerosos desafíos globales, y el compromiso de la UE con el multilateralismo es, ineluctablemente, un compromiso con las Naciones Unidas, «como eje del sistema multilateral» ${ }^{44}$. Las referencias del TUE y del TFUE a las Naciones Unidas y a su Carta fundacional así lo confirman ${ }^{45}$.

La diversidad y amplitud de relaciones entre las Naciones Unidas y la UE han aumentado progresivamente, sobre todo en las dos últimas décadas. El papel activo que juega la Unión en los trabajos de esta Organización es fácilmente constatable si examinamos las numerosas iniciativas de la UE ante la Asamblea General de las Naciones Unidas en diversos ámbi$\operatorname{tos}^{46}$. Y todo esto, desde un mero estatuto oficial de observador.

bros de la UE y de la PESC en Naciones Unidas, en vez de guiarse por el espíritu común de la «identidad europea». RASH, por ejemplo, señala que si bien es una realidad que los logros de la UE en Naciones Unidas han sido claramente mayores en la última década, éstos siguen siendo imperfectos y no han conseguido establecer una representación europea integrada en el seno de las Naciones Unidas. Este autor lo resume afirmando que «Europe itself has not really arrived at the UN». Cfr. el Vade-mecum for streamlining EU Coordination at the 59th session of the UN General Assembly, 28 June 2004 y sobre las medidas para hacer más coherente la representación de la UE en Naciones Unidas, en The European Union at the United Nations: (...)», op. cit., pp. 302 y 310 y ss.

44 Vid., Comisión Europea, La Unión Europea y las Naciones Unidas: la opción del multilateralismo, $\operatorname{COM(2003)~} 526$ final, 10.9.2003, p.3. En este sentido, el nuevo credo adoptado por la UE consistente en un «multilateralismo efectivo» que, en palabras de WOUTERS, HOFFMEISTER y RUYS, ha quedado enmarcado en la Estrategia Europea de Seguridad de 2003, en donde se recoge que el fortalecimiento de las NU constituye una prioridad europea. Cfr. The United Nations and the European Union: An Ever Stronger Partnership, T.M.C. Asser, The Hague, 2006, p. 2 y Estrategia Europea de Seguridad: Una Europa Segura en un Mundo Mejor, 12 de diciembre de 2003, elaborada por el Consejo Europeo, a instancias del antiguo Alto Representante de la UE para la PESC en www.consilium.europa.eu/uedocs/ cmsUpload/031208ESSIIES.pdf

${ }^{45}$ Cfr., entre otros, el artículo 3.5. ${ }^{\circ}$ TUE referente a los objetivos de la Unión en el plano internacional, que se guiarán «por los principios de la Carta de las Naciones Unidas»; dichos objetivos se recogen con mayor concreción en el artículo 21 del TUE, en sus apartados $1 .{ }^{\circ}$ y 2. ${ }^{\circ}$, c); el artículo 34.2. ${ }^{\circ}$ TUE se ocupa de ciertas obligaciones para los Estados miembros de la UE que participen en el Consejo de Seguridad de las Naciones Unidas; ya en el TFUE, el artículo 208.2. ${ }^{\circ}$ alude a las Naciones Unidas en el marco de la cooperación para el desarrollo, el artículo 214.7. ${ }^{\circ}$ TFUE, a la coordinación de la UE con las Naciones Unidas en materia de ayuda humanitaria; también el artículo 220.1. ${ }^{\circ}$ TFUE, como fundamento jurídico expreso sobre las relaciones de la UE con organizaciones internacionales, incluye expresamente los órganos de las Naciones Unidas y sus organismos especializados como actores privilegiados con los que establecerá todo tipo de cooperación adecuada.

${ }^{46}$ Cfr., sobre las ricas y diversas relaciones entre las Naciones Unidas y la UE, en ANDRÉS SAÉZ DE SANTAMARÍA, A., op. cit., nota 26, pp. 136-138, así como en www. eu-un.europa.eu; cfr. nota 41. 
Desde otra perspectiva, la contribución de los Estados miembros de la UE al presupuesto ordinario de la ONU constituye, en conjunto, la mayor aportación financiera si la comparamos con otros miembros, alrededor del $39 \%$ en 2007, superior, por tanto, al $25 \%$ de los EE.UU. ${ }^{47}$.

22. Como futurible, la modificación puntual de la Carta de las Naciones Unidas - y, consecuentemente, el voto afirmativo de los miembros permanentes del Consejo de Seguridad, entre los que se encuentran Reino Unido y Francia - sería obligatoria para permitir que ciertas organizaciones de integración regionales - como la $\mathrm{UE}$ - pudieran adherirse a las Naciones Unidas, fijando los requisitos para que una entidad pudiera ser incluida en esta categoría. Dicha tarea se vería complementada de una labor intensa sobre los acomodos para regular la participación conjunta de la UE y de sus Estados miembros en temas diversos referentes al derecho de expresión, votación, contribución a los gastos de la ONU y participación en los distintos órganos (Consejo de Seguridad, Asamblea General, etc. (Cfr. nota 36).

El acuerdo complejo que permitiera dicha reforma puntual de la Carta de las Naciones Unidas encontraría, actualmente, obstáculos provenientes de los propios Estados miembros de la UE - sobre todo de Reino Unido y Francia-, así como de grupos de Estados diversos que ya han manifestado, con distintos grados de intensidad, su rechazo a posibles cambios en el status quo actual de la UE en la Asamblea General de las Naciones Unidas, dejando ver su incomprensión o no aceptación, prima facie, de las nuevas circunstancias que se presentan para la Unión y sus Estados miembros con el Tratado de Lisboa.

Los desacuerdos a esta posible modificación de la Carta de las Naciones Unidas harían improbable el voto de dos terceras partes de los miembros de la Asamblea General, así como que fueran ratificadas, de acuerdo con sus respectivos procedimientos constitucionales, «por el voto de las dos terceras partes de los Miembros de las Naciones Unidas, incluyendo a todos los miembros permanentes del Consejo de Seguridad» (art. 108 Carta de las Naciones Unidas).

23. En este contexto, impulsado por la entrada en vigor del Tratado de Lisboa y la puesta en marcha del SEAE, la UE comenzó a principios de 2010 a realizar actividades con terceros tendentes a modificar ciertas rutinas en el marco de la AGNU, sin pretender plantear, en este estadio inicial, ni una adhesión en calidad de miembro a las NU, ni una petición formal de

${ }^{47}$ Además, la UE y sus Estados miembros son los principales donantes de ayuda humanitaria, contribuyen con el 56\% de la ayuda al desarrollo, financian casi el $41 \%$ de las operaciones del mantenimiento de la paz en 2007 y aportan el 50\% aproximadamente de las contribuciones a Fondos y Programas. Vid. KNUDSEN, M., op. cit., nota 35, p. 4. 
un estatuto superior al de observador. No obstante, en los meses finales de 2009 , las instituciones de la Unión trabajaban ya en aras de elaborar estrategias para mejorar el estatuto de la UE en Naciones Unidas ${ }^{48}$.

Así, para dar cumplimiento a las disposiciones del Tratado de Lisboa, los Jefes de Misión de los Estados miembros de la UE acreditados ante las NU en Nueva York iniciaron contactos exploratorios con un gran número de representantes de miembros de las NU y con numerosos grupos de Estados. Dichos contactos llegaron casi al centenar y, en algunos de los casos, tuvieron lugar segundas rondas de reuniones, que comenzaron en junio $2010^{49}$.

El objetivo de los contactos era explicar cómo las novedades introducidas en el Derecho de la UE afectaban a su representación exterior en organizaciones internacionales y en concreto en las NU y sus órganos. Se hizo hincapié en la transferencia de responsabilidades desde la Presidencia rotatoria a las nuevas estructuras y representantes. Se quería tomar el pulso a los socios de la UE y, a la vez, miembros de NU, conocer sus reacciones en relación a la necesidad de la nueva UE de cambiar a sus representantes, esto es, al portavoz de la UE hacia las figuras del Alto Representante o Presidente del Consejo Europeo, con vistas a las jornadas célebres de la AGNU como las que inauguran los nuevos periodos de sesiones y cuya próxima convocatoria comenzaba la penúltima semana de septiembre de 2010. De forma ordinaria, la transferencia de responsabilidades se dirigiría también hacia los integrantes de la Delegación de la UE, que participarían y se expresarían en nombre de la Unión en las reuniones formales de la Asamblea General, de acuerdo con lo dispuesto en el artículo 221 del TFUE y el artículo 5.3. ${ }^{\circ}$ de la Decisión del Consejo de 26 de julio de 2010 por la que se establece la organización y el funcionamiento del Servicio Europeo de Acción Exterior ${ }^{50}$.

El acuerdo que la UE ansiaba alcanzar - según el documento citado sobre la implementación del Tratado de Lisboa en las Naciones Unidas en

${ }^{48} \mathrm{Cfr}$. «European Union to seek special status at United Nations», The Times, November 19, 2009, en www.timeonline.co.uk

49 El Jefe de la Delegación de la UE y el Representante Permanente de España ante las NU - como Estado que ejercía la Presidencia en dicho semestre - tuvieron un protagonismo especial en dirigir dichos contactos, elaborando los resúmenes e informes sobre los resultados de dichos contactos. Cfr. Documents with respect to the implementation of the Lisbon Treaty at the UN in New York submit to COREPER, Cabinet of HR/VP Ashton, European Union, Brussels, Cab2/SE/il D(10)846, May/June 2010.

${ }^{50}$ Cfr. el artículo 221 TFUE, nota 10. El artículo 5.3. ${ }^{\circ}$ de la citada Decisión del Consejo indica que: «El Jefe de Delegación recibirá instrucciones del Alto Representante y del SEAE, y será responsable de la ejecución de las mismas» (art. 5.3. ${ }^{\circ}$ ); cfr. dicha Decisión del Consejo, loc. cit., nota 14. 
Nueva York - no pretendía aumentar de forma unilateral los derechos que la Unión dispone en calidad de observador en la AGNU, sino sustituir como portavoz al representante del Estado que ejerce la Presidencia por los establecidos de acuerdo con el Tratado de Lisboa (el Presidente del Consejo Europeo, el Alto Representante de la Unión y los de las delegaciones de la Unión) ${ }^{51}$. La UE justificó que esta propuesta respondía a un cambio sustancial en la representación internacional a escala global, por lo que otros grupos regionales podrían asimismo utilizar este derecho de participación y uso de la palabra conjunto. En la práctica, sin embargo, la concesión de dicha prerrogativa a favor de la UE tendría como efecto claro consolidar el estatuto de observador privilegiado que mantiene de facto, por ejemplo, en cuanto al ejercicio del derecho de expresión en las reuniones de la AGNU.

Así, con ocasión de la sesión ordinaria del periodo de sesiones $65 .^{\circ}$ de la AG, se pretendió llegar a un acuerdo, siquiera informal, para que el Presidente del Consejo Europeo - el Sr. Van Rompuy - interviniera en la sesión inaugural plenaria en la que sólo toman la palabra Jefes de Estado y de Gobierno $^{52}$. En sesiones anteriores en la AGNU, la UE se valió de la intervención del representante de máximo nivel del Estado que ejercía la Presidencia rotatoria del Consejo. Empero, las novedades introducidas por el Tratado de Lisboa en materia de representación exterior, impedían implícitamente la continuación de dicho uso. Dicho acuerdo no se consiguió finalmente. De forma que, el pragmatismo, que suele llevar a arreglos de facto, y del que la UE ha hecho uso en numerosas ocasiones, no funcionó ${ }^{53}$.

24. Los resultados de los contactos mantenidos entre la UE, de un lado, y el casi centenar de Estados miembros de NU y grupos de Estados, de otro,

${ }^{51}$ Cfr. Documents with respect to the implementation of the Lisbon Treaty at the UN in New York submit to COREPER, loc. cit., nota 49, p. 7 y anexo 1. La UE mantuvo contactos en el primer semestre de 2010 en Nueva York con los representantes de distintos grupos regionales: países africanos, países árabes, países latinoamericanos, países del Caribe y asiáticos. De forma más concreta con la Comunidad del Caribe (CARICOM), los Estados SAP (Stabilisation and Association Process), AOSIS (Alliance of Small Island States), la Troika del NAM (Non-aligned Movement), los Estados de la AELC, el grupo de Estados menos desarrollado (LDCs), la Asociación de Naciones del Sudeste Asiático (ASEAN) y GUAM (Organization for Democracy and Economies Developments), entre otros.

52 En el supuesto de que dicho acuerdo informal se hubiera logrado, la UE, probablemente, hubiera consolidado su uso en reuniones posteriores, hasta encontrar el momento adecuado para formalizarlo a través de la adopción de una resolución de la AGNU.

${ }^{53}$ Los acuerdos informales adoptados «sobre la marcha» para que la UE participe en el marco de las NU son frecuentes. El éxito de los mismos se debe a la compresión por parte de los otros Estados miembros de la ONU, habida cuenta de la «buena reputación» de la UE en el marco de la Organización, teniendo en cuento su contribución financiera, su carácter activo en las actividades de la Organización y, de forma más concreta, en los trabajos preparatorios sobre diversos ámbitos en el seno de la AGNU. 
reflejan una mezcla de receptividad a acoger las pretensiones de la Unión relativas a permitir los cambios en la representación de la UE ante la Asamblea General de las Naciones Unidas, junto a ciertas cautelas por las medidas que la Unión pretende adoptar.

Así, de manera conciliadora y diplomática, la mayoría de los miembros de las NU manifestaron su buena voluntad hacia las pretensiones de la Unión, si bien, subrayaron que dichos acuerdos deberían mantener la compatibilidad con la Carta de las NU y otras normas internas, como el Reglamento de la AGNU, sin alterar el estatuto de observador que formalmente tiene la UE y sin conferirle derechos reservados a los Estados miembros de las NU. No obstante, ciertos Estados con los que la UE tiene relaciones especiales - como los de los Balcanes orientales - mostraron su posición clara de apoyar, incluso, un refuerzo en el estatuto de observador de la UE.

Algunos interlocutores pusieron el acento en que las pretensiones de la UE no constituyeran una discriminación o ventaja comparativa entre los miembros de las Naciones Unidas. Algunas organizaciones internacionales que promueven la integración regional y que disponen de estatuto de observador en la AGNU - como la Unión Africana, la ASEAN, el Consejo de Cooperación del Golfo y CARICOM - manifestaron su comprensión hacia la pretensión de la UE, aceptando que el grado de integración que tienen es mucho menor que el de la UE y reconociendo, implícitamente, que sus Organizaciones no han llegado aún al acuerdo interno para solicitar ante la AGNU hablar bajo una misma representación. Por otro lado, la Liga de Estados Árabes, que disfruta también de un estatuto de observador ante la AGNU, dejó entrever en sus contactos con la UE que esta ocasión constituía para ella una oportunidad para solicitar derechos adicionales.

Los motivos que determinaron que finalmente los contactos de la UE no dieran el fruto deseado para quedar representada ante la AGNU, son diversos:

- Las reticencias de ciertos Estados no europeos tuvieron un gran peso en dicho «fracaso de la UE». Entre ellos, destacan los emergentes, que están presionando firmemente en NU y otros foros - como el FMI - para hacer valer su peso económico, alegando a su favor la sobrerrepresentación de los Estados europeos. De hecho, una constante incluida en las justificaciones ofrecidas por los Estados no europeos miembros de las NU y grupos de Estados para rechazar las pretensiones de la Unión se refiere a que ésta ya se encuentra sobrerrepresentada en las Naciones Unidas. Diversos autores añaden distintos matices, v.g., que dicha situación se hace más acusada habida cuenta del desarrollo más comedido de los países de la Unión durante los últimos años, en contraste con la evolución de otros, so- 
bre todo los asiáticos. Se destaca también las reticencias de distintos Estados a aceptar una representación de la UE que sea cumulativa a la de sus Estados miembros en las Naciones Unidas. Por otro lado, también se ha puesto de relieve el hecho de que la ONU no ha tenido nunca vocación de convertirse en una Organización compuesta de organizaciones de integración regional, imperando su clara vocación estatal ${ }^{54}$.

- Los EE.UU. y Rusia, miembros permanentes del Consejo de Seguridad, han marcado una línea roja muy nítida, dejando claro que cualquier apoyo que las NU otorguen a la UE en sus pretensiones de cambio relativas a la participación en las reuniones formales de la Asamblea General, no podrá ser concedida a otro grupo regional u organización internacional.

- De forma contraria a lo mantenido por los EE.UU. y Rusia, otro grupo numeroso de Estados y grupos regionales ha manifestado con firmeza que los cambios que la UE pretende introducir no pueden ser exclusivos para ella, debiendo quedar abiertos para otros observadores que los quisieran aplicar en un futuro ${ }^{55}$.

25. Una vez que la UE fue consciente de la imposibilidad de sacar adelante un acuerdo informal, teniendo en cuenta las contestaciones de los Estados y grupos de Estados con los que había mantenido contactos, decidió optar por elaborar un proyecto de resolución para que fuera adoptado por la AGNU con fecha de 31 de agosto de 2010. El objetivo de esta medida era evitar que cada vez que la UE quisiera intervenir en una reunión formal de la AGNU tuviera que alcanzar un acuerdo ad hoc, rele-

${ }^{54}$ Cfr. HAMONIC, A., op. cit., nota 21, p. 77; GSTÖHL señala al respecto: «In fact, Europe's weight in the global institutions (in terms of seats and/or votes) usually exceeds the relative share in population, and often also in gross domestic product, which it represents», op. cit., nota 26, p. 385; AHEARNE, A., PISANI-FERRY, J., SAPIR, A., VÉRON, N., «Global Governance: An Agenda for Europe» en Bruegel Policy Brief, No. 7, Issue 2006/2007, Bruegel, Brussels 2006, p. 3.

55 Este escollo podría salvarse siguiendo las pautas de actuación utilizadas cuando la UE - entonces CEE - se adhirió a la FAO hace casi dos décadas. La inclusión de una fórmula referida no exclusivamente a la CEE, sino a las «organizaciones de integración (económica) regional» (OIER) consiguió evitar el veto de numerosos Estados que veían en tal ingreso al organismo especializado de las NU, la concesión de un privilegio exclusivo para la UE. La fórmula OIER ha sido utilizada, asimismo, para que la antigua CE pudiera adherirse en calidad de miembro, entre otras, a la CICAA, a la Comisión para la Conservación de los Recursos Marinos Vivos Antárticos (CCRMVA) y a la Comisión del Atún para el Océano Índico (CAOI). En el caso de la AGNU, sería necesario incluir expresamente los requisitos concretos que debe reunir un ente para quedar incluido en dicha categoría - como se hizo en el caso de la $\mathrm{FAO}-$. A corto y medio plazo será prácticamente inviable que otro organismo, además de la UE, reúna los requisitos establecidos. 
gando a la UE a una posición más débil que antes de la entrada en vigor del Tratado de Lisboa, de forma contraria, por tanto, al espíritu de dicho Tratado ${ }^{56}$.

La opción de adoptar una resolución sobre la «participación de la UE en la labor de las Naciones Unidas» fue sugerida por la mayor parte de los interlocutores con los que mantuvieron contactos los representantes de la UE en aras de una mayor claridad y seguridad jurídica, teniendo en cuenta que ésta, además de llevar a cabo un cambio de representante, pretendía buscar derechos adicionales que consolidaran su estatuto de «observador privilegiado» - aunque dicha categoría no apareciera de forma expresa en la resolución $-{ }^{57}$. La Unión Europea se embarcó, de manera optimista y apresurada, en intentar consolidar su estatuto de observador privilegiado, a sabiendas del escaso margen de maniobra del que disponía por la clausura en apenas dos semanas del periodo de sesiones en el que tenía que debatirse y adoptarse la resolución.

26. El debate sobre la adopción del proyecto de resolución presentado por Bélgica, en representación de la UE y sus 27 Estados miembros, ante la Asamblea General de las Naciones Unidas al final del verano de 2010, te-

${ }^{56}$ Un ejemplo de este retroceso en materia de representación exterior de la UE, lo constituye el hecho de que el Presidente del Consejo Europeo, el Sr. Van Rompuy, no pudiera hablar en nombre de la UE en la sesión inaugural del periodo de sesiones $65 .^{\circ}$ de la Asamblea General en septiembre de 2010. Las informaciones publicadas en la propia página web de la UE indicaban, al respecto, que debido a las prácticas existentes en la Asamblea General de las Naciones Unidas durante Debate General del año 2010, al comienzo del periodo de sesiones $65{ }^{\circ}$, la UE, en su calidad de observadora, no había podido participar en el mismo este año. Su contribución se había hecho circular directamente en versión escrita a cada Estado miembro de la ONU explicando que, «con ocasión del Tratado de Lisboa, la UE ha tomado nuevos pasos para impulsar su coherencia, eficacia y eficiencia, ayudando a perseguir los objetivos de las Naciones Unidas». La contribución de la Unión señalaba que las nuevas estructuras permanentes que se han establecido para conducir y llevar a cabo su representación exterior proporcionarán mayor continuidad y harán más sencillo para todos los socios interactuar con la UE. Finalmente indicaba que la UE continuaría las consultas con los miembros de las NU para asegurar la contribución efectiva al trabajo de la Asamblea General de las Naciones Unidas, en www.eu-un.europa.eu/, Ref: EUUN10-085EN

Otro ejemplo muestra cómo en agosto de 2010, el Ministro de Asuntos Exteriores Belga, el Sr. Steven Vanackere - en calidad de representante de la Presidencia rotatoria del Consejo de la Unión - hablara en nombre de la Alta Representante de la UE, la Sra. Catherine Ashton, en una sesión especial de las NU sobre las graves inundaciones en Pakistán, ya que ésta no había tenido la posibilidad de ejercer tal derecho. Cfr. EU Statement - United Nations General Assembly: Floods in Pakistan, 19 August 2010, en www.europa-eu-un.org; UN General Assembly postpones vote on special status for the EU, T. VOGEL, 14.09.2010, www.europeanvoice.com

57 Cfr. Documents with respect to the implementation of the Lisbon Treaty at the UN in New York submit to COREPER, loc. cit., nota 49, p. 4. 
niendo en cuenta que el derecho de expresión ya lo ejercía la UE en este órgano, ponía el acento en cuestiones tales como el orden al hablar en el debate general y otras reuniones formales, el cambio en la portavocía de la Unión $^{58}$, la posibilidad de interactuar en el debate - incluyendo el derecho de responder y plantear cuestiones de orden, presentar enmiendas, formular propuestas, incluidas las de carácter procedimental, disponer de la capacidad de distribuir documentos o llegar a acuerdos relativos al lugar en el que sentarse en la sala de reuniones-, que tiene un gran valor simbólico, ya que a los observadores se les asignan asientos en un lugar de la sala más apartado, que los distingue de los sujetos que tienen el estatuto de miembro; se pide, en este sentido, la asignación de «asientos adecuados para que realicen las acciones mencionadas» ${ }^{59}$.

El día de finalización del periodo de sesiones $64 .^{\circ}$, el 14 de septiembre de 2010, la Asamblea General de las Naciones Unidas decidió posponer la discusión sobre el proyecto de resolución relativo a la "participación de la UE en los trabajos de las Naciones Unidas» para el periodo de sesiones 65. . Los resultados obtenidos al llevarse a votación la posposición del debate fueron de 76 votos a favor (esto es, de Estados que no aceptaban el proyecto de resolución), 71 en contra (países que aceptaban dicho proyecto) y 26 abstenciones. El Grupo Africano, la CARICOM, los pequeños Estados insulares en desarrollo - entre ellos numerosos Estados del Pacífico-, fueron los que

${ }^{58}$ En este sentido, el proyecto de resolución recoge de forma combinada, por un lado, que las novedades del Tratado de Lisboa relativas al cambio de representación de la Unión en el exterior se confían al «Presidente del Consejo Europeo, el Alto Representante del la Unión Europea para Asuntos Exteriores y Política de Seguridad, la Comisión Europea y las delegaciones de la Unión Europea», contando el Alto Representante con la asistencia de un SEAE, que incluye las delegaciones de la UE. Los representantes de la Unión Europea citados, de acuerdo con dicho proyecto, «han asumido la función, anteriormente desempeñada por los representantes del Estado miembro que ocupaba la Presidencia rotatoria del Consejo de la Unión Europea, de actuar en nombre de la Unión Europea en las Naciones Unidas ejerciendo las competencias que les han conferido sus Estados miembros». Por otro, en el inciso 1. del proyecto de resolución se indica que «los representantes de la Unión Europea, a los efectos de participar efectivamente en los periodos de sesiones y la labor de la Asamblea General, incluido el debate general, sus comisiones y grupos de trabajo, en las reuniones y conferencias de las Naciones Unidas, y con el fin de presentar las posiciones de la Unión Europea, serán invitados a hacer uso de la palabra de forma oportuna (...)» (cursiva añadida). El proyecto de resolución recoge, de forma indirecta, el cambio de sus representantes en el seno de la AGNU. Vid. A/64/L.67, proyecto de resolución de la Asamblea General de las Naciones Unidas, 31 de agosto de 2010, en www.un.org

59 Vid. A/64/L.67, ibid. Aunque a simple vista resulten poco relevantes, no hay que subestimar los derechos mencionados vinculados al debate y a la posibilidad de intervenir cómodamente para influir en las posiciones de los Estados, ya que la mayor parte de las resoluciones que se adoptan en la AGNU por consenso, y sólo subsidiariamente se llevan a votación. 
con más firmeza se resistieron a las pretensiones de la UE, solicitando más tiempo para analizar el texto y sus implicaciones, debido a las alteraciones que su adopción tendría en los métodos de trabajo de las $\mathrm{NU}^{60}$.

El desenlace de este paso importante para la UE en su participación en organizaciones internacionales aguarda, mientras que sus esfuerzos a tal fin continúan, paralelamente a la apertura de un periodo de reflexión dentro de la Unión, analizando los fallos en la estrategia seguida.

\section{Reflexiones finales}

27. El establecimiento de un Servicio Europeo de Acción Exterior, y consecuentemente, de un cuerpo diplomático europeo sólido y eficaz, necesita obligatoriamente que las delegaciones de la Unión en los terceros países y ante organizaciones internacionales cooperen y mantengan una colaboración estrecha entre sí y con las misiones diplomáticas y consulares de los Estados miembros acreditadas, y asimismo ante Estados y organizaciones internacionales ${ }^{61}$.

En la práctica reciente, con ocasión del intento de la UE de mejorar su estatuto en la Asamblea General de las NU, desafortunadamente, hemos tenido la oportunidad de comprobar cómo dichos canales de conexión no funcionan adecuadamente. Efectivamente, en algunos casos el motivo por el cual un país específico no votó a favor de los intereses de la UE para mejorar su status en la Asamblea General de las Naciones Unidas se debió, en parte, a una falta de coordinación adecuada entre la delegación de la Unión en este Estado y la delegación de la UE en Nueva York, por un lado, así como de ésta y de las instituciones europeas de Bruselas con las misiones diplomáticas de los Estados miembros de la Unión acreditadas en ese Estado, por otro. De haber sido informados adecuadamente y con

60 Vid. Closing Sixty-Fourth Session, General Assembly President urges concrete actions, 14 September 2010, Plenary, $122^{\text {nd }}$ Meeting (AM), en www.un.org En el anexo de este documento figura el listado de países que votaron a favor y en contra de posponer el debate. Se mostraron, por ejemplo, a favor de las pretensiones de la UE, los EE.UU. y Japón, en contra, China, Rusia o Cuba.

Por otro lado, en las prioridades del Consejo de la Unión y del Parlamento Europeo para el periodo de sesiones $65 .^{\circ}$ de la Asamblea General de las Naciones Unidas, estas instituciones hacen referencia a la adecuación de la UE en las NU, teniendo en cuanta las novedades que incorpora el Tratado de Lisboa en materia de acción exterior; cfr. EU priorities for the 65th United Nations General Assembly, 25.05.2010, en www.europa-eu-un.org

${ }^{61}$ Este ligamen continúa siendo una pieza clave en la articulación del derecho de legación activa de la Unión (vid. el art. 221.2. ${ }^{\circ}$ TFUE, como fórmula heredada de Tratados anteriores, nota 10). 
mayor tiempo, la representación de la Unión acreditada en el país tercero hubiera mantenido los contactos adecuados con los mandatarios estatales competentes, para explicarles sus pretensiones en este punto. De haberse producido estos encuentros, las probabilidades de que dicho Estado fuera más receptivo a las aspiraciones de la UE en Naciones Unidas hubieran sido mayores, trasladando una posición más acorde con las aspiraciones de la Unión desde la capital del país a su representación permanente ante las Naciones Unidas, habida cuenta de las óptimas relaciones que muchos Estados y la UE mantienen ${ }^{62}$.

Este ejemplo, probablemente reproducido en otros puntos de la geografía mundial, no favoreció la adopción de posiciones favorables a la UE por parte de los grupos regionales. La generalización de estos fallos en los canales de comunicación, unido al escaso tiempo para desarrollar la estrategia de la Unión y el contenido ambicioso de las pretensiones de la Unión de la medida a adoptar, determinaron el fracaso de la iniciativa.

28. A bote pronto puede resultar frustrante que, a las puertas de comenzar el nuevo periodo de sesiones $65 .^{\circ}$ de la AGNU, la UE y sus Estados miembros no lograran sacar adelante el proyecto de resolución sobre la «participación de la UE en la labor de las Naciones Unidas». Ni siquiera consiguió la Unión expresarse en la sesión inaugural con los representantes establecidos tras la reforma operada por el Tratado de Lisboa. Ahora bien, la posición más reflexiva que adopto sobre este «aparente desencanto» para la Unión, es optimista y templada. Así, retrospectivamente, examinando el iter de la UE y conociendo las dificultades que ha superado a lo largo de décadas para lograr hacerse un hueco dentro de las organizaciones internacionales - asimilando en ciertos aspectos su actuación a la de los Estados-, no me resulta tan extraordinario que haya habido problemas para sacar adelante esta reforma ambiciosa, en menos de un año desde la entrada en vigor del Tratado de Lisboa.

Efectivamente, los derechos y privilegios incluidos en el proyecto de resolución al final del periodo de sesiones $64 .^{\circ}$ de la AGNU se encuentran muy ligados al estatuto de miembro. Aunque el proyecto de resolución se empeñe en afirmar que «la Unión Europea mantiene su condición de observador en la Asamblea General» (cursiva añadida), no cabe duda de que de haberse adoptado dicha resolución, se hubiera consolidado el esta-

62 En este sentido, RASH se queja de que el cordón umbilical de las misiones permanentes de los Estados miembros de la UE ante las Naciones Unidas se encuentra unido a las capitales de los respectivos países, más que con los órganos de la Unión con sede en Bruselas, lo que da lugar a problemas de coordinación; The European Union at the United Nations: (...), op. cit., nota 41, p. 303. 
tuto de «observador privilegiado o reforzado» para la Unión ${ }^{63}$ o de «participante en los trabajos» en dicho órgano ${ }^{64}$.

La fuerza de la Unión en sus relaciones con numerosos países, grupos de Estados, así como su actuación en foros diversos, hará que, más tarde o temprano, salgan adelante sus pretensiones. Aunque el estatuto privilegiado que la UE pretendía consolidar en la AGNU, incluya derechos que, a simple vista, no parecen tan relevantes, suponen realmente un punto y aparte en las forma de participación tradicionales de los sujetos de Derecho internacional en las organizaciones internacionales, formalizando un estatuto de observador reforzado en el órgano plenario más representativo de toda la sociedad internacional, y que sería solicitado oficialmente, por efecto arrastre, en otros organismos del sistema de las Naciones Unidas y allende ${ }^{65}$.

En definitiva, gracias al impulso de la UE, las fórmulas de participación en las organizaciones internacionales pueden enriquecerse y adquirir modalidades más diversas, que dinamicen unas estructuras diseñadas por y para los Estados ${ }^{66}$.

${ }^{63}$ El convencimiento de que se trataba de consolidar un «estatuto de observador privilegiado» se refleja, de diversas formas en la prensa especializada. Hay referencias al «status especial», se alude a «an attempt by the EU to upgrade its status at UN», inter alia. En www. presseurop.eu; www.eleconomista.es

${ }^{64}$ Las diferencias esenciales entre el estatuto de miembro y el estatuto de observador privilegiado para la Unión o categorías similares, se encuentra en no contar con el derecho de voto - que es típico y exclusivo de los miembros-, así como el la obligación de contribuir al presupuesto de la Organización - aunque es frecuente hacer frente a ciertos gastos administrativos derivados de su actuación como observador o, incluso, llegar a acuerdos con los Estados miembros de la UE en este sentido-.

65 Hay que tener en cuenta que la concesión del estatuto de observador a la UE en 1974 impulsó a que otros órganos de las NU y de otras organizaciones internacionales aceptaran esta participación.

${ }^{66}$ Resulta de rabiosa actualidad el símil que el Prof. Remiro narraba hace más de dos décadas y que resumo infra. La historia contaba las dificultades del saurio que quería ser hombre. Naturalmente no consiguió su deseo, sin embargo «logró la igualdad de trato a partir del reconocimiento de que su diferencia no había de desmerecer su estatuto». La UE —en versión actualizada, antes las Comunidades Europeas - , se encuentra también deseosa de ser tratada como un Estado, por lo que lucha «permanentemente por la adaptación a su peculiar naturaleza de un medio social que no ha sido concebido para ella; se esfuerza por romper las reglas tradicionales y arraigadas de los clubes restringidos de los Estados en cuya promiscua compañía desea moverse; se desgasta en un esfuerzo que requiere ajustes técnicos de textos pensados para los Estados y que, políticamente, han de contar con su asentamiento. Desde un cierto punto de vista la sociedad internacional es segregacionista, inspira la ordenación de sus relaciones en una suerte de apartheid que privilegia a los sujetos estatales. La reivindicación comunitaria es una complicación». Vid. REMIRO BROTÓNS, A., «Las relaciones exteriores de las Comunidades Europeas» en GARCÍA DE ENTERRÍA, E., GONZÁLEZ CAMPOS, J.D., MUÑOZ MACHADO, S. (eds.), Tratado de Derecho Comunitario Europeo, tomo III, Civitas, Madrid, 1986, p. 683. 